\title{
Evolución de las relaciones bilaterales entre Brasil y Chile desde la política "Convergencia en la Diversidad" "
}

\author{
Evolução das relações bilaterais entre \\ o Brasil e o Chile desde a política \\ "Convergência na Diversidade"
}

\author{
Development of Brazil-Chile bilateral \\ relations from the "Convergence in \\ Diversity" policy onwards
}

\author{
Julia de Souza Borba Gonçalves**
}

\begin{abstract}
RESUMEN
En este artículo se argumenta que Chile se ha convertido en el aliado de Brasil para promover la convergencia entre el Mercosur y la Alianza del Pacífico desde el lanzamiento de la política de "Convergencia en la Diversidad" (2014) hasta la actualidad. Se demuestra cómo las percepciones brasileñas sobre Chile se formaron desde el abordaje constructivista de las Relaciones Internacionales y utilizando el process-tracing como método de análisis. Se examinaron las declaraciones y proposiciones brasileñas en las siguientes fuentes: documentos
\end{abstract}

\footnotetext{
* Parte de esta investigación se realizó durante el curso de magíster de autora en el Programa Interinstitucional de Postgrado en Relaciones Internacionales "San Tiago Dantas" (UNESP, UNICAMP, PUC-SP), el cual obtuvo apoyo de la Coordenação de Aperfeiçoamento de Pessoal de Nivel Superior (CAPEs) del Ministerio de Educación (MEC).

** Estudiante de Doctorado en Relaciones Internacionales de la Universidade de Brasília (UnB). Máster en Relaciones Internacionales por el Programa Interinstitucional de Postgrado en Relaciones Internacionales "San Tiago Dantas" (UNESP, UNICAMP, PUC-SP). Investigadora de la Red de Investigación en Política Exterior y Regionalismo (REPRI) y miembro de la Red Colombiana de Relaciones Internacionales (RedIntercol).E-mail: juli.borbagoncalves@ gmail.com o julia.borba@aluno.unb.br. ORCID: https://orcid.org/0000-0002-3148-4808. Recibido: 22 de diciembre de 2020. Aceptado: 15 de noviembre de 2021.
} 
oficiales de los gobiernos brasileños, actas de las reuniones del Grupo Mercado Común, Comunicado Conjunto de los Presidentes del Mercosur, telegramas del Ministerio de Relaciones Exteriores de Brasil y declaraciones disponibles en los sitios web oficiales de Brasil y Chile. Los resultados señalan que la política de "Convergencia en la Diversidad" y los lazos bilaterales con Chile han consolidado la percepción del Brasil de que Chile es su aliado para promover la convergencia entre los bloques y que esa percepción sigue prevaleciendo, pese a los cambios de gobierno en ambos países. También se destaca que tales percepciones han tenido impactos para el fortalecimiento de los lazos bilaterales entre Brasil y Chile en otras áreas.

Palabras Clave: Relaciones bilaterales Brasil y Chile - Convergencia en la Diversidad - Alianza del Pacífico - Mercosur - Prosur.

\section{RESUMO}

Este artigo argumenta que o Chile se tornou aliado do Brasil para promover da convergência entre o Mercosul e a Aliança do Pacífico desde o lançamento da política "Convergência na Diversidade” (2014) até atualmente. Se demonstra como foram se moldando as percepções brasileiras sobre o Chile a partir da abordagem construtivista das Relações Internacionais e utilizando o process-tracing como um método de análise. As declarações e propostas brasileiras foram examinadas nas seguintes fontes: documentos oficiais dos governos brasileiros, atas das reuniões do Grupo Mercado Comum, Comunicado Conjunto dos Presidentes do Mercosul, telegramas do Ministério das Relações Exteriores do Brasil e declarações oficiais disponíveis nos sites oficiais do Brasil e do Chile. Os resultados indicam que a política de "Convergência na Diversidade" e os laços bilaterais com o Chile consolidaram a percepção do Brasil de que o Chile é seu aliado para promover a convergência entre os blocos e que esta percepção persistiu no tempo, apesar das mudanças de governo em ambos os países. Também se destaca que tais percepções tiveram impactos no fortalecimento dos laços bilaterais entre o Brasil e o Chile em outras áreas.

Palavras-chave: Relações bilaterais Brasil e Chile - Convergência na Diversidade - Aliança do Pacífico - Mercosul - Prosul. 


\section{ABSTRACT}

In this article, I argue that Chile became Brazil's ally in order to promote the convergence between Mercosur and the Pacific Alliance from the launch of "Convergence in Diversity" (2014) onwards. I demonstrate how Brazilian perceptions about Chile and its propositions were shaped from the constructivist approach of International Relations and using process-tracing as the method to analyze the data from the following sources: official documents of the Brazilian governments, minutes of Common Market Group's meetings, Joint Communiqué by the Presidents of Mercosur, telegrams of Brazil's Ministry of Foreign Affairs, and official statements available at Brazil's and Chile's official websites. The results point out that the "Convergence in Diversity" policy and the bilateral ties with Chile have consolidated Brazil's perception about Chile being its ally to promote the convergence between the blocs and that such perception still prevails, despite the government changes in both countries. It is also highlighted that such perceptions have had impacts for the strengthening of the bilateral ties between Brazil and Chile in other areas.

Keywords: Brazil and Chile bilateral relations - Convergence in Diversity - Pacific Alliance - Mercosur - Prosur. 


\section{INTRODUCCIÓN}

La Alianza del Pacífico surgió en 2011 en el contexto del fortalecimiento de la gobernanza regional a través de la Unión de Naciones Sudamericanas (Unasur), la cual representó la máxima expresión de la unidad regional que se venía observando desde las transformaciones políticas en América del Sur (Comini; Frenkel, 2014).

Mientras que la conformación de Unasur representó el cambio del regionalismo abierto de la década de 1990 hacia el regionalismo post-liberal y post-hegemónico (Sanahuja, 2016), el surgimiento de la Alianza del Pacífico evidenció las intenciones de Chile, Colombia, México y Perú de retomar el regionalismo abierto, los vínculos de México en América del Sur, y de estrechar los lazos con la región Asia-Pacífico (Malamud; Gardini, 2012).

Los países que conforman la Alianza del Pacífico tienen como característica común la preferencia por el regionalismo abierto, la firma de Tratados de Libre Comercio y la apertura comercial e inserción económica, priorizando la proyección hacia la región Asia-Pacífico (Oyarzún, 2018). La Alianza del Pacífico surgió como contrapeso regional en el eje "Pacífico" a los bloques existentes del eje "Atlántico" como el Mercado Común del Sur (Mercosur), Unasur y Comunidad de Estados Latinoamericanos y Caribeños (Celac), y principalmente al liderazgo brasileño en ese eje, debido a su posición destacada en Mercosur y Unasur (Oyarzún; Rojas, 2013).

Desde entonces, se ha puesto al debate las discusiones sobre la fractura o división en los ejes Atlántico y Pacífico de la integración regional, representada principalmente por el Mercosur y la Alianza de Pacífico, pero que también incorporan al análisis los roles de Unasur y Celac (Sanahuja, 2016).

En 2014, el gobierno de Michelle Bachelet propuso la política "Convergencia en la Diversidad" para discutir las posibilidades de convergencia entre la Alianza del Pacífico y el Mercosur. A partir de entonces se realizaron reuniones entre representantes de ambos bloques para discutir la agenda de convergencia y en 2018 se realizó el primer encuentro de presidentes de la Alianza del Pacífico y del Mercosur, al margen de la Cumbre de la Alianza del Pacífico en México ese mismo año (Itamaraty, 2014a).

A principio, los representantes de política exterior de Brasil adoptaron una postura crítica sobre la creación de la Alianza del Pacífico, sus impactos en la integración regional y, consecuentemente, en el Mercosur. Sin embargo, Brasil propuso a los miembros de Mercosur medidas de acercamiento al bloque en 2014 (Mariano, 2016), y la convergencia se mantuvo en la agenda de política exterior pese a la reorientación del gobierno de Michel Temer en temas relacionados a la integración regional 
(Mariano, 2017). Además, se observó que Chile, entre los países de la Alianza del Pacífico, tuvo un rol relevante en dicho proceso según percepciones del gobierno brasileño (Gonçalves, 2019).

El artículo argumenta que la política "Convergencia en la Diversidad", formulada por Chile para promover la aproximación entre Mercosur y Alianza del Pacífico, llevó a que se consolidara la imagen de Chile como el aliado de Brasil en dicho proceso. Para tal, se examinaron las percepciones presentes de actores claves de la política exterior de Brasil involucrados en dicha temática.

El artículo está organizado en 3 secciones, además de la Introducción y Conclusiones. En la primera sección, se explica la metodología. En la segunda se analiza cómo se fueron consolidando las percepciones brasileñas sobre Chile en la Alianza del Pacífico. Finalmente, en la tercera sección, se demuestra cómo el proceso para la convergencia llevó al estrechamiento de las relaciones bilaterales entre Brasil y Chile y al avance en otros temas de la agenda bilateral.

\section{PeRSPECTIVA TEÓRICA Y MÉTODO DE ANÁLISIS}

En esta sección se explican la perspectiva teórica, los métodos, fuentes e informaciones para analizar cómo se van construyendo las percepciones de actores claves de política exterior de Brasil.

Por ser un trabajo de política exterior, cabe explicar que esta se entiende como la política orientada por un Estado hacia el ambiente exterior (ambientes multilaterales, regionales y bilaterales), pero que, a la vez, es resultado de procesos domésticos donde interactúan distintos actores e intereses. Por ende, se considera a la política exterior como el resultado de las decisiones de gobierno, en que se toman en cuenta los actores y cómo se da la dinámica entre ellos (Salomón; Pinheiro, 2013; Milani; Pinheiro, 2017).

A su vez, el análisis está anclado en el abordaje constructivista de las
Relaciones Internacionales, el cual introdujo la posibilidad de agencia y puso de relieve los procesos de interacciones sociales. Los agentes toman decisiones en procesos de interacción con otros y, al hacerlo, llevan consigo realidades histórica, cultural y políticamente distintas (Fierke, 2006). Son las ideas (normas, identidades e intereses) y cómo estas surgen, difunden y modifican, y quienes se hacen parte de dicho proceso (sean actores estatales o no) que importan para los análisis de política exterior (Salomón; Pinheiro, 2013).

Las ideas sobre el Otro están organizadas en imágenes y revelan las percepciones y creencias sobre sus atributos. La definición de la imagen de aliado, surge "when an international relationship is defined by positive goal interdependence, similar capability, 
and similar cultural status" (Alexander; Levin; Henry, 2005, p.30), la cual facilita la cooperación.

El análisis de Silva (2020) demuestra empíricamente cómo las percepciones de cancilleres brasileños sobre la imagen de Argentina impactaron en el proceso de acercamiento entre Brasil y Argentina en el período de 1974 a 1985, que fue sucedido por una etapa de superación de rivalidades con la firma de la Declaración de Iguaçu, en 1985. Su análisis parte del abordaje cognitivo en análisis de política exterior basándose en Schafer (1997) para afirmar que la construcción de la imagen está relacionada a la percepción histórica del tomador de decisión sobre la naturaleza de la relación bilateral.

Sin embargo, como propone Houghton (2007), en este artículo se adopta la posición de que el análisis de la política exterior debe tomar en cuenta tanto el abordaje de la sicología cognitiva (la construcción individual) como el abordaje constructivista (la construcción social). En ese sentido, la interacción con el Otro es fundamental para la producción de significados. Los análisis sobre el proceso adopción de roles en el escenario internacional, por ejemplo, argumentan que este es el resultado tanto de la auto-percepción del "Self" como de la validación social por el "Other", privilegiando el enfoque de la agencia sobre la estructura, sin dejar de reconocer el poder de las estructuras sobre procesos de decisión en política exterior (Wehner; Thies, 2014). Es decir, la construcción de la imagen de
Chile se da no solamente por aspectos cognitivos por parte de Brasil, sino por su interacción con Chile.

Para responder cómo se consolidó la imagen de Chile como aliado de Brasil, se utilizó el método process-tracing, debido a su utilidad para describir fenómenos políticos y sociales, e identificar una cadena causal, al permitir el uso combinado de distintas fuentes (Collier, 2011). Se emplea el process-tracing para "desnudar la caja negra" de la causalidad al examinar el mecanismo causal existente entre $\mathrm{X}$ e Y (Beach; Pedersen, 2013), donde la política "Convergencia en la Diversidad" (X) llevó a que se consolidara la imagen de Chile como aliado (Y) de Brasil en la Alianza del Pacífico.

Se establecieron 3 mecanismos causales: i) las afinidades políticas entre Brasil y Chile; ii) la intensidad del contacto bilateral; iii) la preferencia por tratar la aproximación Mercosur y Alianza del Pacífico con Chile. Es decir: si la consolidación de la imagen de Chile pasa por las afinidades políticas entre ambos países, las cuales facilitaron la intensidad del contacto bilateral $\mathrm{y}$, consecuentemente, generaron una preferencia de Brasil por Chile sobre los demás países del bloque para tratar el tema de la aproximación Mercosur-Alianza del Pacífico.

Se delimita el caso en el período 2014-2020 debido a que en 2014 surge la política "Convergencia en la Diversidad" y en 2018 el Mercosur y la Alianza del Pacífico establecieron el Plan de Acción. Los avances en ese período se 
han traducido en la consolidación de esa imagen hasta la actualidad.

La imagen de "aliado" no sigue una lógica binaria, es decir, no es el opuesto de "enemigo" (Alexander; Levin; Henry, 2005) y tampoco se sugiere que los demás países de la Alianza del Pacífico lo sean. Se utiliza dicha denominación en concordancia con Fermandois (2016), quien trabaja con la categoría de "aliado" y "aliado místico" al analizar las relaciones bilaterales entre Brasil y Chile

Se analizaron las percepciones de actores clave de la política exterior de Brasil y cómo dichas percepciones fueron estableciéndose a partir de la interacción con Chile: se analizan las percepciones y proposiciones de la figura del Presidente(a) de la República, y ministros(as) de Relaciones Exteriores (Itamaraty) y de Desarrollo, Industria y Comercio Exterior ${ }^{1}$ (MDIC). La elección de estos agentes se justifica debido a que, tradicionalmente, el accionar de la política exterior ha estado concentrado en los dos primeros, legitimados por la Constitución Federal de 1988, pero desde 1990 también ha habido una mayor participación de otras agencias gubernamentales en el proceso decisorio de la política exterior brasileña, lo que Milani y Pinheiro (2017) denominan de proceso de " $h o-$ rizontalização" de la política exterior.

Las fuentes consultadas en este artículo son: documentos oficiales del gobierno brasileño (Mensagem ao Congresso Nacional y agenda y registro de viajes internacionales de la Biblioteca de la Presidencia de la República); actas de las reuniones del Grupo Mercado Común (GMC); comunicados conjuntos de presidentes de Mercosur; declaraciones presidenciales y de ministros de gobierno (registrados en los sitios web oficiales del gobierno y/o en periódicos); telegramas entre el Itamaraty y embajadas brasileñas en los cuatro países de la Alianza del Pacífico.

1 En 2019, bajo el gobierno de Jair Bolsonaro, se creó el Ministerio de Economía, el cuál incorporó 3 Ministerios: Ministério da Fazenda, Ministério do Planejamento y Ministério da Indústria, Comércio Exterior e Serviços (y una parte del Ministério do Trabalho). El MDIC fue dividido en Secretaria Especial de Comércio Exterior e Assuntos Internacionais (SECINT) y Secretaria Especial de Produtividade, Emprego e Competitividade (SEPEC) del nuevo Ministerio de Economía. 


\section{LA CONSTRUCCIÓN DE LA IMAGEN DE CHILE COMO EL ALIADO De Brasil en la Alianza del Pacífico}

Como se ha explicado anteriormente, el surgimiento de la Alianza del Pacífico ha generado discusiones sobre la fractura del regionalismo en los ejes Atlántico y Pacífico (Oyarzún; Rojas, 2013; Sanahuja, 2016), bien como la contraposición al liderazgo brasileño sobre América del Sur (Oyarzún; Rojas, 2013). Sin embargo, a partir de 2014 Chile pasa a promover la política de "Convergencia en la Diversidad", la cual fue crucial para que se realizaran las dos primeras reuniones entre los cancilleres de Mercosur y la Alianza del Pacífico en noviembre del mismo año.

Dicha iniciativa surge en respuesta a las críticas al gobierno de Sebastián Piñera (2010-2014) por haber distanciado a Chile de América Latina. El gobierno de Michelle Bachelet siguió apoyando la permanencia de Chile en la Alianza del Pacífico debido a sus éxitos comerciales y, al mismo tiempo, buscó conciliarlo con Mercosur (con el cual Chile tiene acuerdos con todos sus países y es Estado Asociado desde 1996) para que no se produjeran fracturas ideológicas entre ambos proyectos (Aranda; Riquelme, 2015).

Los representantes de ambos bloques prosiguieron con la agenda de la aproximación y se reunieron en 2015 y 2017, cuando definieron la "Hoja de Ruta”. En 2018 se realizó el primer encuentro presidencial de Mercosur y
Alianza del Pacífico, con la firma del "Plan de Acción" y la "Declaración entre los Estados Partes del Acuerdo Marco de la Alianza del Pacífico y los Estados del Mercosur Partes del Tratado de Asunción", que destacan la defensa del sistema multilateral de comercio y del regionalismo abierto (Mercosur 2018a, 2018b).

Por parte del Mercosur, en 2015 se iniciaron las discusiones sobre la aproximación entre los bloques, principalmente, en el ámbito del GMC — una de sus instancias decisorias-. El país que se encontraba en la Presidencia Pro Témpore (РPT) del bloque presentaba propuestas para tal, es decir, todos los miembros de Mercosur ${ }^{2}$ han aportado significativamente a la agenda y dado continuidad a ella (Gonçalves, 2019). De 2014 a 2018, los presidentes y los ministros de Relaciones Exteriores y MDIC (este último en el período 20152016) fueron actores claves en la conducción de la agenda de aproximación en las relaciones bilaterales, en el GMC y en el nivel de bloques, con destaque para rol de Chile (Gonçalves, 2019).

El artículo argumenta que, de 2014 a 2018, Brasil percibe a Chile como su aliado para promover la aproximación entre Mercosur y Alianza del Pacífico, y que esa percepción ha persistido

2 A excepción de Venezuela, que se encuentra suspendida de Mercosur desde 2016. 
hasta la actualidad. Dicho proceso de aproximación atraviesa los gobiernos de Dilma Rousseff y de Michel Temer, período en el cual se produjo un cambio sustantivo en la postura de Brasil ante América del Sur.

Mientras que el gobierno de Rousseff continuó con directrices generales de la política exterior del gobierno de Lula da Silva, el gobierno de Temer generó cambios en la agenda de política exterior para la región, como el aumento de las críticas a Venezuela, la agenda de apertura comercial de Mercosur, debido a que sus cancilleres eran políticos del PSDB, partido opositor a los gobiernos petistas (Silva; Pérez, 2019). A su vez, el gobierno de Jair Bolsonaro marcó un reordenamiento de alianzas en la región y revisión de las instituciones regionales (Saraiva, 2020).

En las subsecciones siguientes, se explican los tres mecanismos causales: i) las afinidades políticas; ii) la intensidad del contacto bilateral; iii) la preferencia por Chile sobre los demás países de la Alianza del Pacífico para tratar de la aproximación.

\section{Afinidades políticas}

La percepción de que Chile es el aliado en la Alianza del Pacífico se fue construyendo a partir de las interacciones entre las altas autoridades y las afinidades políticas existentes entre ellas, que en el caso analizado se justifica por las percepciones y trayectorias políticas de los actores claves.
Esto se afirma con base en que el conjunto de creencias de actores domésticos deben ser tomados en cuenta en la definición de la política exterior a partir del abordaje constructivista (Solomón; Pinheiro, 2013) y del interaccionismo simbólico (Wehner; Thies, 2014), así como los aspectos cognitivos y las experiencias políticas previas en el país en cuestión (Silva, 2020).

La convergencia de ideologías presidenciales es un factor que contribuye al éxito del regionalismo a medida que en las ideologías articulan ideas sobre autonomía política y búsqueda del desarrollo e inserción económica (Orjuela; Chenou, 2019). Por lo tanto, se evidenciaron las percepciones positivas sobre el Otro y la relación bilateral compartidas por Brasil y Chile en el período 2014-2020 para demostrar las afinidades políticas existentes.

De 2014 a 2016, las afinidades existentes entre las presidentas Rousseff y Bachelet se evidencian en sus preferencias en relación a las políticas sociales y a la importancia de América Latina en sus políticas exteriores, así como sus trayectorias políticas de militantes de izquierda, víctimas de las dictaduras militares y primeras presidentas de Brasil y Chile, respectivamente. Otras figuras importantes que han contribuido con las afinidades políticas entre Brasil y Chile son el canciller Heraldo Muñoz, quien fue embajador en Brasil (1994-1998), y Marco Aurélio Garcia, asesor internacional de la Presidencia de la República durante los gobiernos de Lula da Silva y Dilma Rousseff 
(2003-2016), y que se exilió en Chile durante la dictadura militar brasileña.

En abril de 2016 se inició un conturbado proceso de impeachment resultante de una crisis político-institucional en Brasil que llevó a la destitución de la Presidenta Rousseff y el ascenso de Michel Temer a la presidencia en 2016. Consecuentemente, el cambio de gobierno produjo reorientación en las estrategias globales y regionales de la política exterior (Silva; Pérez, 2019).

Argentina, presidida por Mauricio Macri, fue el primer país en reconocer oficialmente la legitimidad del gobierno de Michel Temer, mientras que la cancillería de Chile publicó una nota en que señalaba la preocupación por los hechos políticos sobre la administración de "la amiga Presidenta Dilma Rousseff" (Ministerio de Relaciones Exteriores, 2016). Cuando la presidenta Bachelet viajó a Brasil en octubre de 2017 para ver el partido de la selección chilena en São Paulo, no viajó a Brasilia para reunirse con el Presidente brasileño. Bachelet sostuvo una audiencia protocolar con el gobernador del Estado de São Paulo, Geraldo Alckmin, y una reunión con el secretario general del Ministerio de Asuntos Exteriores, Marcos Galvão, quien le presentó la propuesta de celebrar una reunión del Mercosur y la Alianza del Pacífico al margen de la Cumbre del Mercosur, en diciembre de 2017 (Valor Econômico, 2017).

La falta de afinidades políticas entre Brasil y Chile, a nivel presidencial, no comprometió el proceso de aproximación entre Mercosur y Alianza del Pacífico. Brasil siguió activo en la agenda al participar de la elaboración de la Hoja de Ruta, firmada en 2017, y al proponer que se realizara una reunión entre Mercosur y Alianza del Pacífico en diciembre -el secretario general del Itamaraty viajó para reunirse con el canciller chileno, los presidentes de Colombia y de Perú, para entregarles la invitación de la reunión (Gonçalves, 2019)-.

También cabe destacar que la aproximación se vió facilitada por los cambios sistémicos, como la postura hostil de Donald Trump al multilateralismo económico; la intensificación de los lazos diplomáticos y económicos de América Latina con Asia-Pacífico, y los cambios políticos en América del Sur a partir de 2015 que impactaron en la agenda de política exterior de los países. Un ejemplo de esto sería " $A r$ gentina's interest in approaching the Alliance, a self-absorbed Brazil with no capacity for leadership, and stagnation in Mercosur, UNASUR, and ALBA" (Oyarzún, 2018, p. 295).

El regreso de Sebastián Piñera a la presidencia de Chile representó también la vuelta de las afinidades políticas entre los presidentes de Brasil y Chile. Tanto Sebastián Piñera como Michel Temer son considerados presidentes de derecha que comparten visiones convergentes en relación a la integración regional, más enfocada en los aspectos comerciales y en la inserción internacional (Orjuela; Chenou, 2019). Los discursos de Temer sobre 
la aproximación entre Mercosur y Alianza del Pacífico durante 2018 enfatizaban la idea de que se formaría "una alianza" entre ambos bloques la primera vez que se hizo ese tipo de declaración fue durante del cambio de mando presidencial de Chile en marzo de 2018 (Temer, 2018; Valor Econômico, 2018)-.

La "Declaración de las Partes" firmada en 2018, en que los presidentes de ambos bloques destacan la defensa del regionalismo abierto, corresponde al momento particular de viraje político en Brasil (Michel Temer) y Argentina (Mauricio Macri), que ha resultado en una nueva agenda de política exterior para la integración regional, privilegiando las negociaciones de acuerdos extra-regionales al ámbito de Mercosur. Esto se sumó a posicionamientos previos de Paraguay y Uruguay en favor de la apertura, que en 2013 habían ingresado a la categoría de Estados Observadores de la Alianza del Pacífico.

Sebastián Piñera buscó mantener con el nuevo gobierno brasileño, que se iniciaría en 2019 , los avances que fueron llevados a cabo durante el gobierno de Michel Temer. Tras el resultado de la primera vuelta en las elecciones presidenciales de Brasil, en octubre de 2018, Piñera demostró su apoyo a Jair Bolsonaro con énfasis en la agenda económica de apertura comercial y privatizaciones (Folha de São Paulo, 2018).

Durante 2019, la relación bilateral se benefició debido a las señales de apoyo que el presidente chileno había enviado al entonces candidato presidencial, Jair Bolsonaro. El pronto apoyo de Piñera llevó a que el gobierno brasileño eligiera a Chile como uno de los tres destinos ${ }^{3}$ visitados por Bolsonaro en 2019, en el ,marco de su primera gira internacional.

$\mathrm{Al}$ elegir a Chile, Brasil señalaba la construcción de una alianza a nivel regional. Según el canciller brasileño (La Tercera, 2019a), las relaciones bilaterales se fundamentaba en la convergencia de ideas en relación a una economía abierta, liberal y basada en valores conservadores. En el encuentro con el presidente chileno, Bolsonaro declaró: "Me parece que somos amigos desde hace mucho tiempo... tengo una gran admiración por su excelencia desde su primer mandato" (El Mercurio, 2019).

$\mathrm{El}$ acercamiento y convergencia entre Brasil y Chile sobre tema regionales desde 2018, e intensificado en 2019, también debe ser entendido como parte del proceso de ascensión de las derechas globales y su relación con América Latina. La ascensión de Michel Temer a la presidencia y la elección de Sebastián Piñera tuvo como consecuencia para la región el cuestionamiento y abandono de las instituciones regionales y la integración, como el caso de Unasur en 2018, y la creación del Foro para el Progreso y Desarrollo de América del Sur (Prosur) en 2019 (Sanahuja; López, 2020).

3 A excepción del viaje a la reunión del Foro Económico Mundial en Davos. 
Además de examinar las afinidades políticas a partir de las convergencias ideológicas, aquellas también se expresaron en la presencia durante ceremonias de cambio presidencial en
2014, 2015, 2018 y 2019. El Gráfico 1 sistematiza los encuentros bilaterales entre presidentes de Brasil y Chile de 2014 a 2019.

Gráfico 1 Encuentros presidenciales bilaterales entre Brasil-Chile de 2014 a 2019

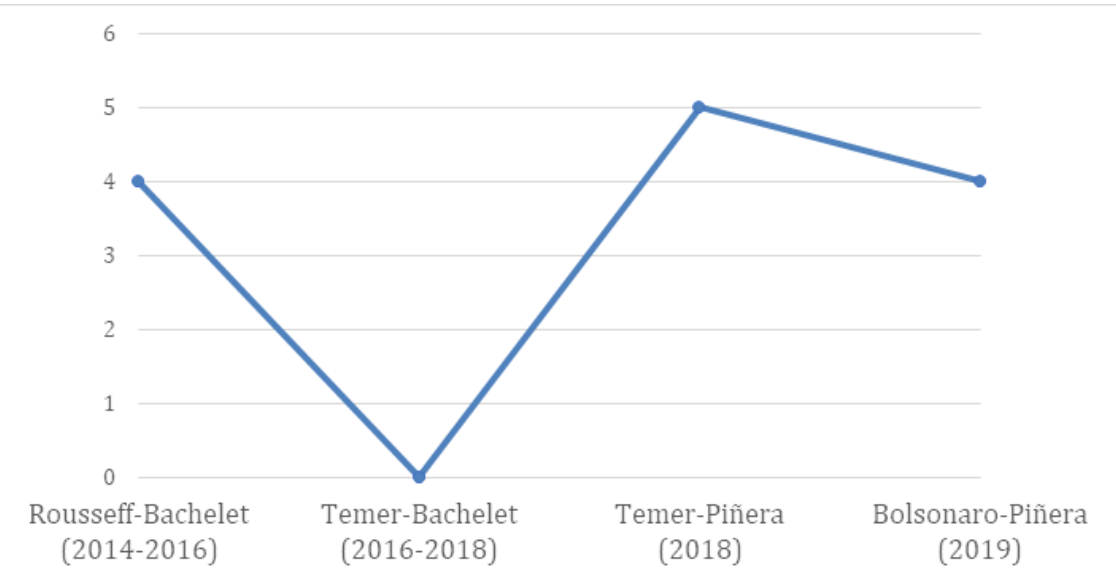

Fuente: Brasil (2020b; 2020c), Itamaraty (2020a).

Los encuentros presidenciales se realizaron justamente en los períodos de mayor afinidad entre presidentes: 4 encuentros en el período $\mathrm{Ba}-$ chelet-Rousseff (2014-mayo/2016), 5 encuentros en el período Piñera-Temer (2018) y 4 encuentros en el período Bolsonaro-Piñera (2019). Durante el período Temer-Bachelet (maio/2016-2018) no hubo encuentros bilaterales. De los encuentros que se realizaron, cabe destacar que los presidentes chilenos estuvieron presentes en los cambios de mando en Brasil en 2015 y 2019, y los mandatarios brasileños estuvieron presentes en los cambios de mando en Chile 2014 y 2018.
Intensidad del contacto bilateral
El segundo mecanismo causal es la intensidad del contacto bilateral durante todo el período. Se sistema- tizó la ocurrencia de los encuentros bilaterales con el objetivo de entender cómo aquella se distribuye en el pe- ríodo. En la Tabla 1 se sistematizaron 
los encuentros bilaterales entre Brasil y los países de la Alianza del Pacífico a nivel de presidentes, cancilleres y ministros de MDIC durante el período 2014 y 2018.

Tabla 1

Reuniones bilaterales a nivel de presidentes, cancilleres y ministro del MDIC (Brasil) de 2014 a 2018

\begin{tabular}{lrrrrrr} 
Chile & $\mathbf{2 0 1 4}$ & $\mathbf{2 0 1 5}$ & $\mathbf{2 0 1 6}$ & $\mathbf{2 0 1 7}$ & $\mathbf{2 0 1 8}$ & Total \\
\hline Presidente & 2 & 1 & 1 & & 5 & 9 \\
MRE & 3 & 1 & 1 & 1 & 3 & 9 \\
MDIC & & 1 & 2 & & 1 & 4 \\
& & & & & & $\mathbf{2 2}$
\end{tabular}

Colômbia

\begin{tabular}{|c|c|c|c|c|}
\hline \multirow{2}{*}{$\begin{array}{l}\text { Presidente } \\
\text { MRE }\end{array}$} & 1 & 3 & & 2 \\
\hline & & 3 & & 2 \\
\hline$M D I C$ & & 2 & 1 & 1 \\
\hline
\end{tabular}

México

$\begin{array}{lllllll}\text { Presidente } & 1 & 2 & & & 1 & 4 \\ \text { MRE } & & 3 & 2 & 2 & & 7 \\ \text { MDIC } & & 2 & & 2 & & 4\end{array}$

Peru

\begin{tabular}{lllll} 
Presidente & & 1 & & 1 \\
MRE & & 1 & 1 \\
MDIC & 1 & 1 & 1 & 3 \\
\cline { 2 - 4 } & & & 5
\end{tabular}

Fuente: Brasil (2020b; 2020c), Itamaraty (2020a).

De los cuatro países de la Alianza del Pacífico, Chile es con quien Brasil ha tenido más encuentros bilaterales en total, entre 2014 y 2018, y en todos los niveles.
Los encuentros bilaterales liderados por el MDIC corresponden a la agenda internacional del Ministerio, bajo la gestión de Armando 
Monteiro $^{4}$, de buscar una aproximación con estos países en el ámbito bilateral y también en el marco del Plano Nacional de Exportações 5 (2015-2018) (Gonçalves, 2019), que tuvo continuidad bajo la gestión de los ministros Marcos Jorge y Marcos Pereira durante el gobierno de Michel Temer.

Otro rasgo distintivo de los encuentros entre Brasil y Chile a partir de 2014, es que todos discuten temas relacionados a la aproximación entre Mercosur y la Alianza del Pacífico, a excepción de la "Reunião do Diálogo Político-Militar Brasil-Chile (Mecanismo 2+2)". Eso no se observa con la misma frecuencia en los encuentros bilaterales de Brasil con los demás países de la Alianza del Pacífico.

La intensidad del contacto está relacionada con los efectos de la socialización internacional, en que el contacto prolongado y continuo son condiciones para la internalización de normas (Checkel, 2005). Por lo tanto, es necesario ir más allá de la constatación de la cantidad de encuentros

4 Armando Monteiro, cuando aún era senador, participó de las primeras discusiones en el Senado Federal sobre los impactos de la Alianza del Pacífico en 2013.

5 El Plano Nacional de Exportações consistía en la política del MDIC de 2015 con el objetivo de aumentar la presencia de las empresas brasileñas en el mundo hasta 2018, identificando los 32 mercados prioritarios para de Brasil, 10 de los cuales son latinoamericanos: Argentina, Bolivia, Chile, Colombia, Paraguay, Perú, Uruguay, Venezuela, Cuba y México. (evidencia de contacto), y examinar si hubo mención a la aproximación entre Mercosur y Alianza del Pacífico durante los encuentros (evidencia de intensidad) entre cancilleres, ministros brasileños y sus contrapartes chilenas a lo largo del tiempo, y cuáles son las percepciones de actores claves en la política exterior de Brasil sobre el rol de Chile en dicho proceso.

Como ya se ha mencionado, Brasil tenía una postura escéptica sobre la Alianza del Pacífico y pasó a señalar el interés de acercar el Mercosur a la Alianza del Pacífico a partir de 2014 (Mariano, 2016). Eso se debe, principalmente, a las discusiones sobre la Alianza del Pacífico en las sesiones de las Comisiones de Relaciones Exteriores y Defensa del Congreso Nacional, que se iniciaron en mayo de 2013. La primera sesión para discutir el rol de la Alianza del Pacífico en la región fue motivada por la firma del Protocolo Adicional al Acuerdo Marco de la Alianza del Pacífico en el mismo mes y cuáles podrían ser los efectos de este nuevo bloque sobre la industria brasileña y el rol de Mercosur en la región. El canciller brasileño, Antonio Patriota, fue convocado a participar de la sesión mediante la convocatoria de los senadores de dicha Comisión (Gonçalves, 2019).

Chile fue el único que demostró preocupación al respeto de las declaraciones del canciller brasileño en aquella sesión. Según el telegrama de la embajada brasileña en Santiago, las declaraciones en tono crítico del 
entonces canciller brasileño sobre la Alianza del Pacífico tuvo amplias repercusiones en Chile, las cuales fueron analizadas tanto por la cancillería chilena como por el equipo de la entonces candidata presidencial Michelle Bachelet (Itamaraty, 2013a).

Estas discusiones en el ámbito doméstico llevaron a que Brasil elaborara una agenda propia para acercar Mercosur a los países de la Alianza del Pacífico. Durante la sesión de las Comisiones de Relaciones Exteriores y Defensa Nacional en el Senado Federal, en febrero de 2014, el canciller brasileño señaló que se estaba formulando una agenda en el ámbito del Mercosur para la desgravación arancelaria con los países de la Alianza del Pacífico y, en mayo del mismo año, Brasil presentó dos propuestas en el ámbito del GMC sobre el tema (Gonçalves, 2019).

Pese a que Brasil empezó a formular esta agenda de acercamiento a la Alianza del Pacífico ya en 2013, la iniciativa de Chile fue fundamental para que se materializara la propuesta de aproximar el Mercosur y la Alianza del Pacífico y para que Brasil reconociera el rol protagónico de Chile. Eso debido a que la política de "Convergencia en la Diversidad" surgió también para acercar Chile a Brasil, al enfatizar que la Alianza del Pacífico no se contrapone a Unasur y que Brasil es un "socio estratégico" para Chile.

Como señala en el telegrama del Embajador de Brasil en Chile en 2014:
A aproximação com o Brasil que se aguarda e se anuncia nos círculos governamentais, sinalizada pelos encontros que Vossa Excelência manteve com o Chanceler chileno, a 3 de março, e pela reunião entre as Primeiras-Mandatárias, a 11 do mesmo mês, à margem da cerimônia de posse de Michelle Bachelet, seria fator de fortalecimento politico de um governo que iniciou seu mandato disposto a avançar nas reformas estruturais e acenou com guinada expressiva na política externa (Itamaraty, 2014b) ${ }^{6}$.

6 En la misma nota, el Embajador destaca que: "Por outro lado, cresce em diversos interlocutores o sentimento de que a oposição de centro-direita desejaria que os movimentos de reaproximação explicitados por Bachelet e Muñoz não resultassem em gestos de reciprocidade do lado brasileiro, caracterizando um insucesso do governo da Nova Maioria que comprovaria que o distanciamento do Brasil nada mais é do que a expressão de uma política externa que busca hegemonia na América Latina e não está disposta a exceder-se em demonstrações de carinho com o Chile, seja o Presidente Piñera ou Bachelet. $O$ artigo de Joaquín Fermandois, que mal disfarça a pouca simpatia com o Brasil, recomenda que o Chile se aproxime do nosso país com os olhos abertos, insinuando que o novo governo estaria equivocado ao depositar no Brasil expectativas de reaproximação baseadas em afinidades entre as duas presidentas". El artículo de Fermandois fue publicado en el periódico "El Mercurio". Disponible en: https:// w w w. e $1 \mathrm{~m} \mathrm{e} \mathrm{r} \mathrm{c} \mathrm{u} \mathrm{r} \mathrm{i} \mathrm{o.co} \mathrm{m} \mathrm{/}$ blogs/2014/04/01/20697/A-Brasil-conlos-ojos-abiertos.aspx. 
A principios de marzo de 2014, Heraldo Muñoz y el canciller brasileño Luiz Alberto Figueiredo sostuvieron una reunión para debatir las visitas oficiales del canciller y la presidenta chilena a Brasil, la integración latino-americana y la convergencia entre el Mercosur y la Alianza del Pacífico (Itamaraty, 2014c). En mayo de 2014, por invitación de Muñoz, el canciller Figueiredo viajó a Chile para participar del debate "El diálogo Atlántico-Pacífico y Oportunidades de Comercio e Inversión en América Latina", del Consejo Consultivo Empresarial de la APEC para discutir las perspectivas de integración económica en América del Sur, y las exportaciones brasileñas al Pacífico a partir de la expansión de la infraestructura chilena y sudamericana (Itamaraty, 2014d).

En junio, durante la visita oficial de Bachelet a Brasil, las presidentas firmaron el memorando sobre el "Intercâmbio de documentação para o esclarecimento de graves violações aos Direitos Humanos" (Itamaraty, 2014e), y la Confederação Nacional de Indústrias (CNI) y la Sociedad de Fomento Fabril (sOFOFA) suscribieron una declaración sobre la diversificación de las relaciones comerciales bilaterales, en que la CNI destacó su interés por acompañar los avances de la Alianza del Pacífico y acercarse a Chile por ser un importante mercado importador (Portal da Indústria,
2014). Ese ya era un interés previo de la CNI, cuando en diciembre de 2013 ambas agrupaciones debatieron sobre cómo empresas brasileñas podrían aprovechar las oportunidades generadas por la Alianza del $\mathrm{Pa}$ cífico, debido al interés de la CNI en explorar nuevos mercados frente al estancamiento en las negociaciones comerciales del Mercosur (Itamaraty, 2013b).

Tras la Cumbre Presidencial de Mercosur, en diciembre de 2014, la presidenta brasileña declaró su aprecio hacia Chile por haber tenido la iniciativa de promover el diálogo entre los bloques (Rousseff, 2014), siendo este un indicativo de la internalización del interés de promover la convergencia según lo que se discutió en las reuniones ministeriales entre el Mercosur y la Alianza del Pacífico, en noviembre de ese mismo año.

Eso se ve más explícitamente en 2015, en su segundo gobierno, cuando se indicó que Brasil tendría una agenda de comercio exterior más activa que incluiría la relación con la Alianza del Pacífico (Brasil, 2015), y cuando el ministro Armando Monteiro señaló que el diálogo con la Alianza del Pacífico debería ser una prioridad para Brasil en materia de comercio exterior durante 2015 (Comex do Brasil, 2015).

A principios de abril de 2015, el director de la Dirección General de Relaciones Económicas Internacionales 
(DIRECON) $)^{7}$, Andrés Rebolledo, y el Embajador de Brasil en Chile sostuvieron una reunión de trabajo para discutir el proceso de convergencia, donde el director mencionó el envío de la propuesta de la "agenda corta" para apreciación por parte de los miembros de Mercosur (Itamaraty, 2015a). El diálogo entre el Mercosur y la Alianza del Pacífico, principalmente la "agenda corta", fue el tema tratado durante la visita oficial del canciller brasileño, Mauro Vieira, a Chile el 16 de abril. Los demás temas bilaterales abordados fueron la cooperación en las áreas de energía, ciencia y tecnología, defensa, inversión e infraestructura (Itamaraty, 2015b; Itamaraty, 2015c).

Durante la XCVII Reunión Ordinaria del GMC de Mercosur, realizada en la misma fecha del viaje del canciller brasileño a Chile, la РPт brasileña envió a sus pares en el Mercosur, la propuesta "Plan de Acción" " para el diálogo de Mercosur y Alianza del Pacífico a ser presentado primeramente al Grupo de Alto Nivel de la Alianza del Pacífico. La misma contemplaba los temas definidos en la

7 Actualmente nombrada Subsecretaría de Relaciones Económicas Internacionales (SUbReI).

8 El Plan de Acción de 2015 aborda los siguientes tópicos: profundización de los ACES; certificado de origen; participación de las empresas del Mercosur en las Macro Ruedas de Negocios de la Alianza del Pacífico; acumulación de origen; ventanillas únicas para el comercio exterior; y cooperación aduanera. "agenda corta" discutida con el director de la DiRECon (Mercosur, 2015a, 2015b).

En noviembre de 2015, el ministro del MDic lideró una misión empresarial a Chile para firmar el acuerdo de facilitación de inversiones y cooperación. En la ocasión, se discutió la convergencia entre Mercosur y Alianza del Pacífico, y su viaje tuvo una repercusión positiva en la prensa chilena, según el telegrama enviado por la Embajada brasileña (Itamaraty, 2015e, 2015f).

Durante su visita oficial a Chile, en febrero de 2016, la presidenta Rousseff vuelve a declarar su aprecio por la iniciativa chilena de promover el diálogo entre los bloques para construir un acercamiento estratégico en América del Sur (Rousseff, 2016). En abril del mismo año, el ministro del MDIC estuvo en la Reunión de Seguimiento Comercial entre Brasil y Chile, donde se destacó la necesidad de fortalecer los lazos comerciales y de inversión entre ambos países (Comex do Brasil, 2016).

El 10 abril de 2017, tres días después del encuentro ministerial del Mercosur y la Alianza del Pacífico que estableció la "Hoja de Ruta", el canciller brasileño, Aloysio Nunes, viajó a Chile para tratar temas bilaterales, entre los cuales estaba la convergencia entre los bloques. La nota compartida por Itamaraty destaca que "en el ámbito de América del Sur, los gobiernos de Brasil y Chile se han comprometido a aproximar la 
Alianza del Pacífico y el Mercosur"9 (Itamaraty, 2017).

En 2018, a inicios del gobierno de Sebastián Piñera (2018-2022), el canciller y el Presidente chileno realizaron visitas oficiales a Brasil para tratar la agenda bilateral. Por ocasión del encuentro presidencial, Itamaraty publicó una nota en que reconoce que "los dos países [Brasil y Chile] son promotores del proceso de aproximación entre el Mercosur y la Alianza del Pacífico, una iniciativa destinada a profundizar la integración regional" ${ }^{10}$. En la declaración presidencial conjunta, ambos presidentes "reafirmaron el compromiso de Brasil y Chile de profundizar el diálogo y la aproximación entre el Mercosur y la Alianza del Pacífico, mediante la implementación de la 'Hoja de Ruta' definida en la reunión de Buenos Aires, el 7 de abril de 2017"11 (Itamaraty, 2018a, 2018b, 2018c).

En 2018 también fue anunciado el inicio de las negociaciones del Acuerdo Bilateral de Libre Comercio entre los países, propuesta por el presidente Sebastián Piñera, para negociar los temas que no estaban en los acuerdos previamente existentes, como el ACE35. En total, hubo cuatro rondas de negociaciones durante 2018 y se firmó el acuerdo en noviembre de ese

9 Traducción propia.

10 Traducción propia.

11 Traducción propia. mismo año ${ }^{12}$ (Itamaraty, 2018d). Según la nota de Itamaraty, el Acuerdo de Libre-Comercio "al mismo tiempo, constituirá un vector de aproximación entre Mercosur y la Alianza del Pacífico y de fortalecimiento de la integración regional" ${ }^{13}$.

Durante la visita oficial del presidente brasileño a Chile, en 2019, en el contexto de la creación del Prosur como sustituto de Unasur, Sebastián Piñera y Jair Bolsonaro firmaron la Declaración Conjunta. En el documento, los presidentes señalaron el compromiso de ambos países de profundizar el diálogo y la aproximación entre Mercosur y Alianza del Pacífico durante la PPT de Brasil y Chile en los bloques (Itamaraty, 2019a), siendo este el primer punto abordado en la declaración. Los cancilleres de Brasil y Chile sostuvieron una reunión oficial en Brasília en septiembre de 2019, en que discutieron temas relacionados con la integración, como la aproximación entre Mercosur y Alianza del Pacífico (Itamaraty, 2019b)

12 El nuevo acuerdo complementa el ACE-35 al incluir 17 temas de la naturaleza no arancelarias, como el comercio de servicios; el comercio electrónico; las telecomunicaciones; las medidas barreras sanitarias y fitosanitarias; obstáculos técnicos al comercio; facilitación del comercio; propiedad intelectual; y micro, pequeñas y medianas empresas, además de incorporar acuerdos que ya habían sido firmados por ambos países, como el Protocolo sobre Compras Públicas y el Protocolo sobre Inversiones en Instituciones Financieras (Itamaraty, 2018d).

13 Traducción propia. 
Sin embargo, en los documentos "Mensagem ao Congresso Nacional" no se menciona la convergencia entre Mercosur y Alianza del Pacífico como un asunto que se dará prioridad en el gobierno vigente (Brasil, 2019, 2020a) — tema que sí estuvo presente en los documentos de 2015 a 2018-. Por parte de Chile, durante la Cumbre virtual de Mercosur, en julio de 2020, Piñera declaró que no se ha avanzado más en la convergencia tras la firma del Plan de Acción y que la convergencia debería ser retomada para enfrentar los desafíos generados por la pandemia del Covid-19 (La Tercera, 2020), que ha sido el tema prioritario en la agenda internacional y regional desde la aparición de los casos, en marzo de 2020.

Preferencia para tratar de la aproximación Mercosur y Alianza del Pacífico con Chile

Las afinidades políticas y la intensidad del contacto bilateral entre Brasil y Chile generaron una preferencia por tratar la aproximación Mercosur-Alianza del Pacífico. Eso se observa al analizar el tratamiento que el gobierno brasileño le da a su relación con Chile para abordar la aproximación de los bloques en comparación con los demás países de la Alianza del Pacífico.

Brasil propuso incluir la convergencia entre Mercosur y Alianza del Pacífico en la agenda oficial de la reunión de Consultas Políticas Brasil-Chile en dos ocasiones: en agosto de 2014 y junio de 2015 (Itamaraty, 2014f, 2015g), siendo Chile el único país de la Alianza del Pacífico con el cual Brasil discutió la agenda de convergencia durante reuniones de Consultas Políticas. En 2015, la PPт brasileña en el Mercosur envió la propuesta de "Plan de Acción", debatida durante la XCVII Reunión Ordinaria del GMC, para la apreciación de la PPT mexicana en la Alianza del Pacífico y también del gobierno chileno (Itamaraty, 2015d).

Otra manera de corroborar el argumento sobre esa preferencia es examinar el intercambio de telegramas que abordan el tema "Alianza del Pacífico" entre el Itamaraty y las Embajadas brasileñas en los países de la Alianza del Pacífico, de 2011 a 2018. En los Gráficos 2 y 3 se sistematizaron los envíos a fin de verificar si hay un flujo de información con determinada Embajada en el período total y por año. 
Gráfico 2 Envío de telegramas sobre la Alianza del Pacífico de las embajadas brasileñas al MRE. (Distribución de telegramas por año y puesto de la embajada)

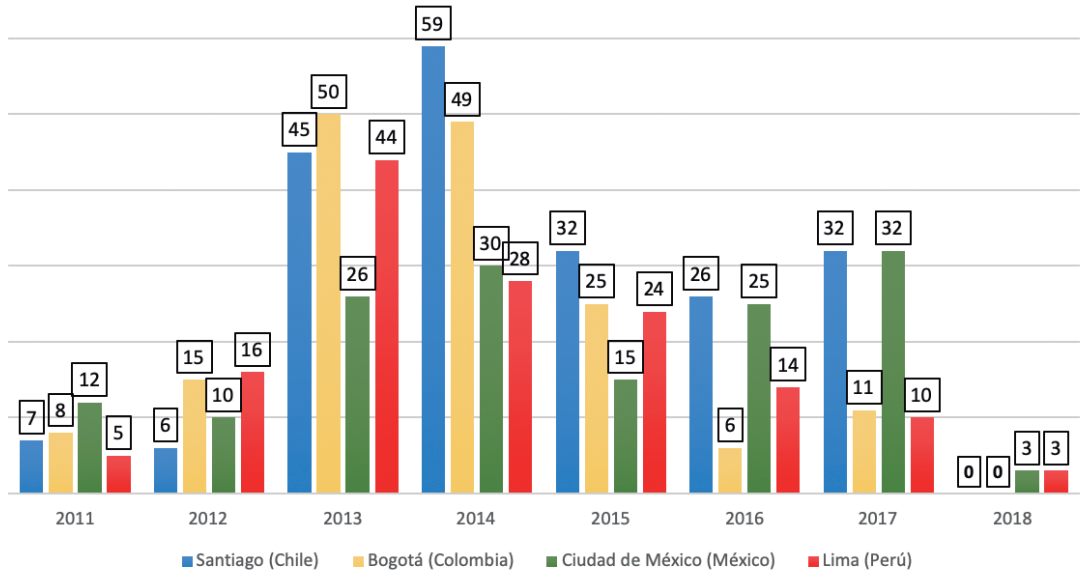

Fuente: Elaboración propia a partir de información recopilada de Itamaraty.

\section{Gráfico 3}

Envío de telegramas sobre la Alianza del Pacífico del MRE a las embajadas brasileñas. (Distribución de telegramas por año y puesto)

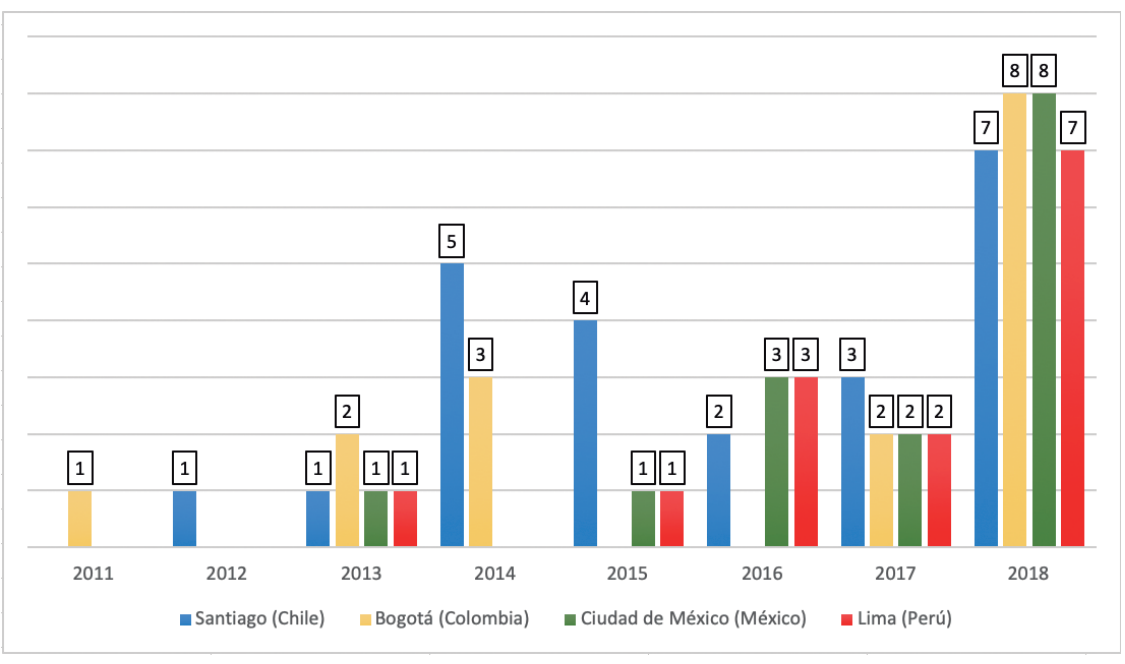

Fuente: Elaboración propia a partir de información recopilada de Itamaraty. 
Tabla 2

Mención a la Alianza del Pacífico en las páginas web de Itamaraty sobre Chile, Colombia, México y Perú

\begin{tabular}{|c|c|c|c|c|}
\hline & Chile & Colombia & México & Perú \\
\hline $\begin{array}{c}\text { Mención a la } \\
\text { Alianza del } \\
\text { Pacífico }\end{array}$ & $\begin{array}{l}\text { "No âmbito sul-americano, o Chile é } \\
\text { parceiro fundamental do Brasil. Os dois } \\
\text { países compartilham o entendimento de } \\
\text { que as iniciativas de integração econômica } \\
\text { regional em curso são convergentes e } \\
\text { trabalham juntos para promover o diálogo } \\
\text { entre a Aliança do Pacífico e o } \\
\text { MERCOSUL" }\end{array}$ & $\begin{array}{l}\text { "Brasil e Colômbia atuam conjuntamente } \\
\text { também no âmbito regional. Ambos são } \\
\text { membros fundadores do PROSUL - Foro } \\
\text { para o Progresso da América do Sul - e do } \\
\text { Grupo de Lima, bem como parceiros no } \\
\text { esforço de aproximação entre a Aliança do } \\
\text { Pacífico e o MERCOSUL." }\end{array}$ & - & - \\
\hline
\end{tabular}

Fuente: elaborado por la autora a partir Itamaraty (2020b).

A partir de los Gráficos 2 y 3 se puede inferir que el flujo de información sobre la Alianza del Pacífico, entre 2014 y 2018 , se concentró en la Embajada de Brasil en Chile, con un total de 207 telegramas enviados al Itamaraty, seguido por la Embajada en Colombia (164), México (153) y Perú (144). A partir de 2014, año en que se formula la política de "Convergencia en la Diversidad", los telegramas enviados por la Embajada brasileña en Chile pasan a superar los envíos de las Embajadas brasileñas en los demás países de la Alianza del Pacífico.

En sentido inverso, el Itamaraty de Brasil envió más telegramas a la Embajada en Chile (23), seguido por la Embajada en Colombia (16), México (15) y Perú (14), superando las demás en cantidad de telegramas enviados también en 2014.

En septiembre de 2020, durante la sesión de las Comisiones de Relaciones Exteriores y Defensa Nacional del Senado Federal, se aprobó la indicación del nuevo Embajador de Brasil en Chile, quien reconoció el liderazgo del país en promover la convergencia. En el documento preparado por Itamaraty se argumentó que "Chile es un socio clave de Brasil. Los dos países comparten el entendimiento de que las iniciativas de integración económica regional en curso, son convergentes y trabajan juntos para promover el diálogo entre el Mercosur y la Alianza del Pacífico" ${ }^{14}$. De la misma manera, se reconoció que "Chile ha sido, dentro de la Alianza del Pacífico, el principal impulsor de la aproximación con el Mercosur, del cual es Estado Asociado desde 1996" 15 (Senado Federal, 2020).

La forma que la Alianza del Pacífico está citada en las páginas web de Itamaraty, como se puede visualizar en la Tabla 2, también revela la preferencia por tratar la aproximación con Chile.

14 Traducción propia.

15 Traducción propia. 
Por lo tanto, podemos afirmar que el contacto continuo e intenso entre Brasil y Chile, a partir de 2014, sobre el tema de la convergencia entre Mercosur y Alianza del Pacífico resultó en la imagen de Chile como el aliado de Brasil para promover dicha aproximación. La interacción tuvo impactos directos en los avances en la agenda de trabajo entre Mercosur y Alianza del Pacífico, como se ha visto en las discusiones bilaterales sobre la "agenda corta".

La imagen sobre Chile se consolidó como el resultado de las interacciones entre actores claves de política exterior, que compartieron sus visiones y moldearon sus percepciones mutuamente. Las percepciones de Brasil sobre Chile y sobre su rol en el proceso de "Convergencia en la Diversidad" se han mantenido en el tiempo, pese al cambio de gobierno en ambos países y de agenda de política exterior.

La política "Convergencia en la Diversidad" fue formulada durante el gobierno de Michelle Bachelet y su sucesor, Sebastián Piñera, ha mantenido el proceso de aproximación en la agenda de política exterior (a pesar de no mantener el mismo nombre en su discurso oficial) y promoverla junto con las negociaciones del Acuerdo Bilateral de Libre Comercio con Brasil.

\section{LAS RELACIONES BILATERALES BRASIL Y CHILE TRAS LA POLÍTICA "CONVERGENCIA EN LA DIVERSIDAD”}

En esta sección se examinan los temas de la agenda bilateral desde 2014 y cómo ellos están relacionados a ese proceso de consolidación de la imagen de Chile como aliado de Brasil. Según Fermandois (2016), la relación con Brasil se destaca por el ideal de Chile sobre ese país: Brasil ha tenido un rol de "aliado místico" para Chile, debido al pasado conflictivo con sus vecinos, lo que ha llevado a Chile a considerarse un aliado de Brasil (Fermandois, 2016).

Los análisis sobre las relaciones bilaterales contemporáneas entre Brasil y Chile (Fonseca, 2006; Fermandois, 2016; Wehner, 2016) coinciden en señalar que ellas se intensificaron a partir de la década de 1990 con la redemocratización en el Cono Sur y concomitantemente a la formación de bloques de integración regional en América Latina. En relación a temas de integración regional, los autores señalan el rechazo chileno a la invitación de Brasil para incorporarse al Mercosur y, en su lugar, privilegiar las negociaciones para un futuro tratado de libre comercio con Estados Unidos.

La decisión de Chile provocó "frustración" para Brasil (Fonseca, 2006), principalmente por la forma en que se dió a conocer y por haber 
ocurrido durante el período de mayor proximidad entre los presidentes Fernando Henrique Cardoso y Ricardo Lagos. El anuncio hecho por el ex presidente Lagos sobre el inicio de las negociaciones de un Tratado de Libre Comercio con EE.UU. indicaba la negativa de ingresar al Mercosur como Estado Parte y adoptar el Arancel Común Externo del bloque. Chile rechazaba, por lo tanto, el proyecto de integración defendido por Brasil y frustraba sus expectativas sobre el rol chileno en la integración regional (Wehner, 2016).

Tal percepción sobre el rol de Chile en la integración regional tuvo continuidad en los gobiernos siguientes. Según el ex canciller Celso Amorim (2011), en su primera visita a Chile como ministro de Relaciones Exteriores durante los mandatos de Lula da Silva, el cuerpo diplomático de la embajada brasileña en Santiago le aconsejó mantener la conversación solo en temas bilaterales. Eso refleja la opción de Chile por adherir al rol de defensor del libre comercio y regionalismo abierto, contrastando con la preferencia brasileña de que tuviera un rol más integracionista en América del Sur (Wehner, 2016). Fermandois (2016) señala la ausencia de visitas de Estado ${ }^{16}$ de la ex presidenta Dilma Rousseff a Chile durante su

16 A pesar de no haber realizado una Visita Oficial de Estado, la presidenta Rousseff sí viajó a Chile en 2013, con motivo de la Cumbre Celac-UE, y sostuvo una reunión de trabajo con el presidente Piñera. primer mandato (2011-2014), considerando que en ese período había viajado a Perú.

En relación a la agenda de infraestructura física, desde 2015 Brasil y Chile participan del proyecto del "Corredor Vial Bioceánico", que conectará Porto Murtinho, en Mato Grosso do Sul, a los puertos del Norte de Chile, pasando por Paraguay y Argentina, y es considerado el proyecto que impulsará la convergencia entre Mercosur y Alianza del Pacífico (Barros, et al, 2020).

Los corredores bioceánicos cumplen el objetivo de concretizar el rol de Chile como "país puente" entre América Latina y Ásia, en que la relación cooperativa con Brasil es de importancia estratégica (Artaza, 2007).

Durante los gobiernos de Lula da Silva y Michelle Bachelet (20062010), Brasil y Chile impulsaron el proyecto del corredor bioceánico pasando por Bolivia (Wehner, 2016). En el proyecto actual el tramo pasa por la región Chaco de Paraguay y el noroeste de Argentina.

Pese a que, de los países de la Alianza del Pacífico, Chile apenas participa del Corredor, este es el proyecto de infraestructura elegido para impulsar la convergencia entre bloques que conectará el Océano Atlántico al Pacífico a través de Brasil y Chile, además de resaltar la relevancia del tema de corredores bioceánicos en la agenda bilateral.

En relación a la infraestructura digital, en 2020 Brasil y Chile firmaron 
el "Memorándum de Entendimiento sobre Cooperación en el Área de Telecomunicaciones y Economía Digital", con el objetivo de profundizar la cooperación digital (Itamaraty, 2020b). En 2021, Brasil adhirió al proyecto "Humboldt", iniciativa para establecer el cable submarino entre América del Sur, Oceanía y Ásia, impulsado por Chile. La adhesión brasileña se suma a otros temas de la agenda de gobierno, como la conexión 5G (Itamaraty, 2021).

En relación a la temática de Defensa, se realizaron la primera y segunda reunión del Diálogo Político-Mili$\operatorname{tar}$ (Mecanismo 2+2) en agosto de 2018 y julio de 2019. En la primera se firmó el protocolo complementario sobre "catalogação de elementos de abastecimento ou elementos de provisões da Defesa de ambos os Estados" y la Declaración de Ministros de Defensa sobre la Cooperación en Ciberdefensa (Itamaraty, 2018e). En julio de 2019, se discutieron las prioridades estratégicas regionales y globales, cooperación antártica, participación de ambos países en misiones de paz, la implementación de la Resolución 1325 del Consejo de Seguridad de las Naciones Unidas (ONU), y cooperación en Ciberdefensa, tomando en cuenta la declaración de ministros de 2018 sobre esa temática (Ministerio de Relaciones Exteriores, 2019).

En relación al comercio bilateral, Chile es el segundo socio de Brasil en América del Sur y Brasil es el principal socio comercial para Chile en la misma región. Los principales productos exportados de Brasil a Chile son crudos de petróleo, carnes, vehículos, automóviles y tractores. Por su parte, los productos exportados de Chile a Brasil son los derivados del cobre, salmón y vino. Sin embargo, el promedio anual del intercambio comercial de 2014 a 2019 fue de $-1,9 \%$, y el comercio bilateral de 2019, en comparación al año anterior, se redujo en 14,7\% (Itamaraty, 2020; SUBREI, 2020a). En relación a las inversiones, Brasil es el primer destino de las inversiones chilenas en el mundo, representando el $29 \%$ del total y se concentran en Servicios (42,5\%), Energía $(27,9 \%)$, Industria $(27,6 \%)$, Agropecuario/Silvícola (1,7\%) y Minería (0,3\%) (SUBREI, 2020b).

En el ámbito regional, Brasil y Chile integran el Grupo de Lima y Prosur. Han participado de todas reuniones del Grupo de Lima, el cual fue creado en 2017 para proponer una resolución a la crisis en Venezuela. El Grupo de Lima pasó a integrar la dinámica de cerco, como el evento Venezuela Live Aid en Cúcuta 
$(\text { Colombia })^{17}$, a Venezuela junto a la Organización de Estados Americanos y al gobierno estadounidense de Donald Trump, que incluye sanciones y el no reconocimiento del gobierno de Nicolás Maduro (Aranda; Bórquez, 2020).

Durante el año 2019, antes del “estallido social", la agenda internacional del presidente Piñera buscó demostrar cierto activismo en temas internacionales. Chile ejerció la Presidencia Pro Tempore de Prosur y de la Alianza del Pacífico, sería la sede de la Cumbre de APEC y de la COP25 - las cuales no se realizaron en el país debido al "estallido social". Piñera realizó una visita a Bolsonaro al regresar a Chile tras la reunión del G7 para proponer mediar la crisis entre Brasil y Francia, motivadas por la postura del presidente brasileño en relación a las quemadas en la Amazonia.

En esta nueva etapa de las relaciones bilaterales, cabe señalar que, a pesar de las convergencias en temas de política exterior, como la participación de ambos países en el Grupo de Lima y su relación con EE.UU. sobre la crisis en Venezuela, la relación ha

17 El presidente Piñera viajó a Cúcuta (Colombia) para entregar ayuda humanitaria en la frontera con Venezuela y para presionar -junto a Juan Guaidó, al canciller brasileño, a los presidentes de Colombia y Paraguay- al gobierno de Nicolás Maduro. El episodio fue conocido como "Cucutazo", que generó críticas por académicos y políticos de la oposición en Chile. atravesado momentos conturbados por las declaraciones de Bolsonaro sobre Pinochet, que ha generado más ruidos sobre el gobierno de Piñera que sobre el de Bolsonaro, quien en ningún momento se ha retractado por los dichos.

Al examinar las declaraciones de Bolsonaro, se observa que su admiración por el modelo chileno de apertura económica está relacionada a la percepción de que el éxito de la economía liberal de Chile se debe al período dictatorial, centrado en la figura del ex general Augusto Pinochet. Es una visión que se manifestó en la época en que Bolsonaro era todavía diputado federal y que se ha mantenido hasta el momento.

El listado de ejemplos es significativo y señala para la continuidad de dicho entendimiento: en 2006, Bolsonaro entró en contacto con la Embajada de Brasil en Santiago, solicitando que se transmitiera el mensaje de solidaridad para el nieto de Pinochet, en que decía que "el mundo sabe que el alto índice de desarrollo humano [...] se debe en gran medida a las acciones emprendidas en el gobierno del difunto General Pinochet" (O Estado de S. Paulo, 2018) y, más de diez años después, en 2017, Bolsonaro vuelve a declarar que Pinochet había salvado Chile (El Mercurio, 2017). En 2019, declaró que Chile "só não é uma Cuba graças aos que tiveram a coragem de dar um basta à esquerda em 1973, entre esses comunistas o seu pai brigadeiro 
à época", en respuesta a la declaración de Michelle Bachelet sobre la reducción del espacio democrático en Brasil (Folha de São Paulo, 2019). Antes del plebiscito de 2020, Bolsonaro publicó en su cuenta oficial en Twitter una imagen de la campaña del "Rechazo" que critica el modelo económico de Argentina, Cuba y Venezuela, reproduciendo el discurso de los apoyadores de dicha campaña ${ }^{18}$.

Piñera ha tratado de blindar la relación de las controversias causadas por Bolsonaro al adoptar una postura distanciada de los dichos del presidente brasileño, pero reconociendo las afinidades existentes entre sí con vistas a estrechar la relación con Brasil y garantizar los compromisos establecidos, como la aprobación del Acuerdo de Libre Comercio Brasil-Chile en el Congreso brasileño.

Respecto de la declaración de Bolsonaro sobre Bachelet, Piñera afirmó no compartir "en absoluto la alusión hecha por el Presidente Bolsonaro respecto de una ex Presidenta de Chile y, especialmente, en un tema tan doloroso como la muerte de su padre". Para blindar las relaciones de dichas declaraciones, hechas justo en el día de la visita a Brasil del entonces canciller chileno Teodoro Ribera, él mismo declaró que "Chile y Brasil tienen intereses comunes y una relación histórica, que trasciende coyunturas y gobiernos" y que su viaje a Brasil tuvo por "finalidad de avanzar hacia una relación de mayor amistad y de colaboración estratégica en los más variados campos" (La Tercera, 2019b).

Otro momento que revela el acercamiento ideológico fue durante el "estallido social", cuando el presidente chileno declaró que "estamos en guerra con un enemigo poderoso" motivado por el informe de la $\mathrm{Di}$ rección de Inteligencia Nacional del Ejército (DINE), el cual no descartaba injerencias externas en las protestas fomentadas por agrupaciones de izquierda (El Mostrador, 2020).

Según el periódico brasileño UOL, una fuente anónima reveló que militares brasileños y chilenos se reunieron y que estos últimos solicitaron que Brasil accionase su inteligencia militar para identificar el origen de los protestos (a los cuales Bolsonaro había dicho que "no eran protestas, sino actos terroristas"). La contraparte brasileña consideró que Open Society, de George Soros, y el Foro de São Paulo pudiesen ser responsables por fomentar las protestas (Uol, 2020). Cabe recordar que en 2018, ambos países firmaron sendos documentos sobre el estrechamiento de la relación bilateral en el área de Defensa, principalmente de la ciberseguridad.

18 Disponible en: https://twitter.com/jairbolsonaro/status/1316329427308023808. 


\section{Conclusiones}

El objetivo del artículo fue demostrar cómo se fueron consolidando las percepciones de actores relevantes de la política exterior brasileña sobre Chile ser el aliado de Brasil en la Alianza del Pacífico. A partir de la política "Convergencia en la Diversidad", Chile buscó acercar a Brasil a los temas discutidos en el país y de interés común, como la invitación a la reunión del Consejo Consultivo Empresarial de la APEC y la reunión para discutir la "agenda corta"; al paso que Brasil respondió reconociendo el liderazgo chileno en la Alianza del Pacífico para promover la convergencia en dos momentos: al incluir el tema en las reuniones de Consultas Políticas y al enviar la propuesta del Mercosur al gobierno chileno, a pesar de que este no estaba presidiendo la pPT de la Alianza del Pacífico.

La relación entre Brasil y Chile durante el período 2014-2018 fue sustancial para avanzar con la agenda de convergencia entre Mercosur y Alianza del Pacífico, de modo que se fue consolidando la percepción de Brasil de que Chile es su aliado para promover la convergencia. Esta percepción ha sido compartida tanto por las figuras presidenciales, miembros del cuerpo diplomático de Brasil, ministro del MDIC, y gremios empresariales, relacionadas también con la importancia de fomentar la agenda comercial regional dada la caída de la economía brasileña.
Particularmente, la afinidad entre presidentes de ambos países fue una variable relevante, ya que está relacionado con cómo perciben y evalúan uno al otro, y cómo se traduce en políticas para la relación bilateral.

Entre 2014 y 2020, la relación bilateral entre Brasil y Chile ha estado en sintonía, con más períodos de afinidad política, en que ambos países han impulsado coordinadamente proyectos regionales (convergencia Mercosur-Alianza del Pacífico, Corredor Vial Bioceánico, Prosur) y temas bilaterales (Acuerdo de Libre Comercio Brasil-Chile y Mecanismo $2+2$ ).

Sin embargo, hay que destacar que a partir de 2019, las relaciones bilaterales son marcadas por una visión particular del presidente brasileño que, al mismo tiempo que le da apoyo a los compromisos existentes y los proyectos impulsados por Chile, como Prosur, también tiene efectos sobre la relación bilateral, en que el presidente chileno responde distanciándose de los dichos del mandatario brasileño, pero reafirmando las afinidades y los lazos bilaterales para preservar los compromisos adoptados.

El artículo busca contribuir a la literatura especializada sobre el regionalismo latinoamericano y sudamericano, dado que la aproximación entre la Alianza del Pacífico y Mercosur sigue siendo tema actual 
y relevante para el área. Busca también contribuir a la literatura sobre Política Externa Brasileña (РEB), sea en los procesos de toma de decisión o el rol de las ideas en políticas exteriores y, más específicamente, intenta contribuir a los estudios sobre las relaciones bilaterales entre Brasil y
Chile. El artículo plantea la posibilidad de seguir explorando las relaciones bilaterales entre estos países, sea en los temas regionales o en asuntos bilaterales específicos, y examinar dicha relación desde una perspectiva de largo plazo.

\section{Bibliografía}

Alexander, M.; Levin, S. y Henry, P.J. (2005). "Image Theory, Social Identity, and Social Dominance: Structural Characteristics and Individual Motives Underlying International Images" [versión electrónica]; Political Psychology, Vol. 26, no. 1, pp. 27-45.

Amorim, C. (2011). Conversas com jovens diplomatas. São Paulo: Benvirá. Aranda, G. y Riquelme, J. (2015). “¿Es posible la Convergencia en la Diversidad?: Chile entre la Alianza del Pacífico y el Mercosur" [versión electrónica]. Revista de Relaciones Internacionales, Estrategia y Seguridad, Vol. 10, no. 2, pp.155-178. Recuperado el 12 de diciembre de 2020 de http://www.scielo. org.co/pdf/ries/v10n2/v10n2a08.pdf. Aranda, G. y Bórquez, A. (2020). "La cuestión venezolana y la fractura del regionalismo latinoamericano" [versión electrónica]. Historia 396, Vol. 10, no. 1, pp. 33-72. Recuperado el 14 de diciembre de 2021 de http://www. historia396.cl/index.php/historia396/ article/view/397

Artaza, M. (2007). “Chile y Asia hoy: una mirada crítica” [versión electrónica].
Estudios Internacionales, no. 156, pp. 55-65. Recuperado el 14 de diciembre de 2021 de https://revistaei.uchile.cl/ index.php/REI/article/view/14315.

Barros, Pedro et al. (2020). Corredor bioceânico de Mato Grosso do Sul ao pacífico: produção e comércio na rota da integração sul-americana. Campo Grande: UEMS.

Beach, D. y Pedersen, R. (2013). Process-Tracing Methods: Foundations and Guidelines. Ann Arbor: University of Michigan Press.

Brasil. Biblioteca da Presidência da República (2020b). Dilma Vana Rousseff. Recuperado el 14 de diciembre de 2020 de http://www.biblioteca.presidencia.gov.br/presidencia/presidencia/ ex-presidentes/dilma-rousseff

Brasil. Biblioteca da Presidência da República (2020c). Michel Miguel Elias Temer Lulia. Recuperado el 14 de diciembre de 2020 de http://www. biblioteca.presidencia.gov.br/presidencia/presidencia/ex-presidentes/ michel-temer/michel_temer

Brasil. Mensagem ao Congresso Nacional. (2020a). Recuperado el 14 de 
diciembre de 2020 de https://www. gov.br/planalto/pt-br/mensagempresidencial/mensagem-ao-congresso-2020. pdf

Brasil. Mensagem ao Congresso Nacional. (2019). Recuperado el 14 de diciembre de 2020 de https:/www12.senado. leg.br/noticias/arquivos/2019/02/04/ mensagem-presidencial

Brasil. Mensagem ao Congresso Nacional. (2015). Recuperado el 14 de diciembre de 2020 de https://www.gov.br/ casacivil/pt-br/centrais-de-conteudo/ publicacoes/mensagem-ao-congresso-nacional/mensagem-ao-congresso-2015.pdf/view

Collier, D. (2011). "Understanding Process Tracing” [versión electrónica]. Political Science and Politics, no. 4, pp. 823-830. Recuperado el 12 de diciembre de 2020 de https://polisci.berkeley. edu/sites/default/files/people/u3827/ Understanding\%20Process \%20Tracing.pdf

Comex do Brasil (2016). Brasil e Chile buscam reforçar o intercâmbio comercial e estimular investimentos bilaterais. Recuperado el 14 de diciembre de 2020 de https://www.comexdobrasil.com/brasil-e-chile-buscam-reforcar-o-intercambio-comercial-e-estimular-investimentos-bilaterais/.

Comex do Brasil (2015). MDIC quer ampliar comércio com a Aliança do Pacífico que somou US\$ 25,6 bilhões em 2014. Recuperado el 14 de diciembre de 2020 de https:/webcache.googleusercontent.com/search?q=cache:5-2xby3rY8sJ:https://www. comexdobrasil.com/mdic-quer-am- pliar-comercio-com-alianca-pacifico-que-somou-us-256-bilh o e s - e m - $2014 /+\&$ c $\mathrm{d}=1 \& \mathrm{hl}=\mathrm{pt}-\mathrm{BR} \& \mathrm{ct}=\mathrm{clnk} \& \mathrm{gl}=\mathrm{br}$.

Comini, N. y Frenkel, A. (2014). "Una Unasur de baja intensidad: modelos en pugna y desaceleración del proceso de integración en América del Sur" [versión electrónica]. Nueva Sociedad, no. 250, pp. 1-20. Recuperado el 12 de diciembre de 2020 de https:// www.nuso.org/media/articles/downloads/4016_1.pdf.

Checkel, J. (2005). "International Institutions and Socialization in Europe: Introduction and Framework" [versión electrónica]. International Organization, Vol, 59, no. 4, pp 801826. Recuperado el 14 de diciembre de 2021 de https://doi.org/10.1017/ S0020818305050289

El Mercurio (2019). “Jair Bolsonaro tras reunión bilateral con Piñera: 'Avanzaremos, ya que Chile es nuestro segundo socio comercial'". 23 de marzo de 2019. Recuperado el 14 de noviembre de 2021 de https://www.emol.com/noticias/Nacional/2019/03/23/942175/ Jair-Bolsonaro-tras-reunion-bilateral-con-Pinera-Avanzaremos-ya-que-Chile-es-nuestro-segundo-socio-comercial.html

El Mercurio (2017). “Lo que me pondrá en el Palacio de Planalto es mi estilo... y yo quiero a Brasil en primer lugar”. 11 de noviembre. Recuperado el 14 de diciembre de 2020 de http://www. economiaynegocios.cl/noticias/noticias.asp? $\mathrm{id}=415905$ 
El Mostrador (2020). El "Plan Zeta" de Piñera: el informe de la DINE sobre la amenaza extranjera que hizo que el Presidente hablara de guerra. 20 de octubre. Recuperado el 14 de diciembre de 2020 de https://www.elmostrador. cl/destacado/2020/10/20/el-plan-zetade-pinera-el-informe-de-la-dine-sobrela-amenaza-extranjera-que-hizo-queel-presidente-hablara-de-guerra/

Fermandois, J. (2016). "Brazil: Chile's mythical ally”, en Gardini, Gian Luca; Tavares de Almeida, Maria H. (eds.), Foreign policy responses to the rise of Brazil. Londres : Palgrave Macmillan, pp. 77-89.

Fierke, K. (2006). "Constructivism”, en Dunne, Tim; Kurki, Milja; Smith, Steve (orgs), International Relations Theories: discipline and diversity. Nueva York : Oxford University Press, pp. 166-184.

Folha de São Paulo (2019). Bolsonaro ataca pai de Bachelet, morto sob Pinochet, e defende golpe no Chile. 4 de septiembre. Recuperado el 14 de diciembre de 2020 de https://www1.folha. uol.com.br/mundo/2019/09/bolsonaro-ataca-pai-de-bachelet-que-foi-torturado-e-morto-pela-ditadura-pinochet.shtml

Folha de São Paulo (2018). Presidente chileno apoia Bolsonaro e diz que 'ninguém conhece' Haddad. 9 de octubre. Recuperado el 14 de diciembre de 2020 de https://www1.folha.uol. com.br/poder/2018/10/presidente-chileno-apoia-bolsonaro-e-diz-que-ninguem-conhece-haddad.shtml
Fonseca, G. (2006). "Brasil y Chile: anotaciones sobre cuarenta años de relaciones bilaterales (1966-2006)" [versión electrónica]. Estudios Internacionales, Vol. 39, no. 154 pp. 117 138. Recuperado el 12 de diciembre de 2020 de https://revistaei.uchile.cl/ index.php/REI/article/view/14481

Gonçalves, Julia de Souza Borba (2019). Brasil e a Aliança do Pacífico: visões em disputa na integração regional? (Tesis magíster en Relaciones Internacionales) Programa Interinstitucional de Postgrado en Relaciones Internacionales "San Tiago Dantas" (UNESP, UNICAMP, PUC-SP).

Houghton, D. (2007). "Reinvigorating the Study of Foreign Policy Decision Making: Toward a Constructivist Approach" [versión electrónica]. Foreign Policy Analysis, Vol. 3, no. 1 pp. 24-45. Recuperado el 28 de junio de 2021 de https://academic.oup.com/ fpa/article-abstract/3/1/24/1793147

Itamaraty (2021). Adesão brasileira ao projeto do cabo de fibras óticas "Humboldt" - Nota Conjunta do Ministério das Relações Exteriores e do Ministério das Comunicações. 15 de mayo de 2021. Recuperado el 14 de diciembre de 2021 de https:// www.gov.br/mre/pt-br/canais_atendimento/imprensa/notas-a-imprensa/ adesao-brasileira-ao-projeto-do-cabo-de-fibras-oticas-201chumboldt201d-nota-conjunta-do-ministerio-das-relacoes-exteriores-e-do-ministerio-das-comunicacoes

Itamaraty (2020). Acordo internacional: assinado Memorando de 
Entendimento entre o Brasil e o Chile sobre Cooperação na área de Telecomunicações e Economia Digital. 27 de julio de 2020. Recuperado el 14 de diciembre de 2021 de https:// www.gov.br/casacivil/pt-br/assuntos/ noticias/2020/julho/acordo-internacional-assinado-memorando-de-entendimento-entre-o-brasil-e-o-chile-sobre-cooperacao-na-area-de-telecomunicacoes-e-economia-digital

Itamaraty. (2020a). Relações Bilaterais. Recuperado el 14 de diciembre de 2020 de https://www.gov.br/mre/pt-br/ assuntos/relacoes-bilaterais/americas

Itamaraty (2019a). Declaração Conjunta Presidencial e Plano de Trabalho por ocasião da Visita Oficial à República do Chile de Sua Excelência o Presidente da República Federativa do Brasil, Jair Bolsonaro - Santiago, 23 de março de 2019. Recuperado el 14 de diciembre de 2020 de https://www. gov.br/mre/pt-br/canais_atendimento/imprensa/notas-a-imprensa/2019/ declaracao-conjunta-presidencial-e-plano-de-trabalho-por-ocasiao-da-visita-oficial-a-republica-do-chile-de-sua-excelencia-o-presidente-da-republica-federativa-do-brasil-jair-bolsonaro-santiago-23-de-marco-de-2019.

Itamaraty (2019b). Visita ao Brasil do ministro das Relações Exteriores da República do Chile, Teodoro Ribera - Brasília, 5 de setembro de 2019. 5 de septiembre de 2019. Recuperado el 14 de noviembre de 2021 de https://www. gov.br/mre/pt-br/canais_atendimento/imprensa/notas-a-imprensa/2019/ visita-ao-brasil-do-ministro-das-relacoes-exteriores-da-republica-do-chile-teodoro-ribera-brasilia-5-de-setembro-de-2019

Itamaraty (2018a). Visita ao Brasil do ministro de Relações Exteriores do Chile, Roberto Ampuero - Brasília, 18 de abril de 2018. Recuperado el 14 de diciembre de 2020 de https:// www.gov.br/mre/pt-br/canais_atendimento/imprensa/notas-a-imprensa/ visita-ao-brasil-do-ministro-de-relacoes-exteriores-do-chile-roberto-ampuero-brasilia-18-de-abril-de-2018

Itamaraty (2018b). Visita do presidente do Chile, Sebastián Piñera - Brasília, 27 de abril de 2018. Recuperado el 14 de diciembre de 2020 de http://webcache.googleusercontent.com/search?q=cache: dyRMfO8ok_MJ:www.itamaraty.gov.br/ pt-BR/notas-a-imprensa/18731-visita-do-presidente-do-chile-sebastian-pinera $+\& \mathrm{~cd}=1 \& \mathrm{chl}=\mathrm{pt}-\mathrm{BR} \& \mathrm{ct}=-$ clnk\&gl=br

Itamaraty (2018c). Atos adotados por ocasião da Visita de Estado. Recuperado el 20 de noviembre de 2020 de http://www.itamaraty.gov.br/ pt-BR/notas-a-imprensa/18748-documentos-adotados-por-ocasiao-da-visita-de-estado-do-presidente-do-chile-sebastian-pinera-brasilia-27-de-abril-de-2018.

Itamaraty (2018d). Conclusão das $\mathrm{Ne}$ gociações do Acordo de Livre Comércio entre o Brasil e o Chile. Recuperado el 14 de diciembre de 2020 de http://antigo.itamaraty.gov.br/pt-BR/ notas-a-imprensa/19656-conclusao- 
das-negociacoes-do-acordo-de-livrecomercio-entre-o-brasil-e-o-chile-santiago-16-a-19-de-outubro-de-2018.

Itamaraty (2018e). Atos assinados por ocasião da Primeira Reunião do Diálogo Político-Militar Brasil-Chile (Mecanismo 2+2) - 9 de agosto de 2018. Recuperado el 14 de diciembre de 2020 de http://antigo. itamaraty.gov.br/pt-BR/notas-a-imprensa/19266-atos-assinados-por-ocasiao-da-primeira-reuniao-do-dialogo-politico-militar-brasil-chile-mecanismo-2-2-9-de-agosto-de-2018

Itamaraty (2017). Visita do ministro Aloysio Nunes Ferreira ao Chile - 10 e 11 de abril de 2017. Recuperado el 14 de diciembre de 2020 de http:// webcache.googleusercontent.com/ search?q=cache:GPi91Mk_xbIJ:www. itamaraty.gov.br/pt-BR/notas-a-imprensa/16080-visita-chile+\&c$\mathrm{d}=1 \& \mathrm{hl}=\mathrm{pt}-\mathrm{BR} \& \mathrm{ct}=\mathrm{clnk} \& \mathrm{gl}=\mathrm{br}$

Itamaraty (2015a). Telegrama ${ }^{\circ} 00372$ enviado por la Embajada brasileña en Santiago (Chile) en 08 de abril.

Itamaraty (2015b). Telegrama no 00170 enviado por el MRE a la Embajada brasileña en Santiago (Chile) en 26 de marzo.

Itamaraty (2015c). Visita do Ministro das Relações Exteriores ao Chile. Recuperado el 14 de diciembre de 2020 de https://www.gov.br/mre/pt-br/canais_ atendimento/imprensa/notas-a-imprensa/visita-do-ministro-das-relacoes-exteriores-ao-chile.

Itamaraty (2015d). Telegrama n 00299 enviado por el MRE a la Embajada brasileña en Santiago (Chile) en 21 de mayo.

Itamaraty (2015e). Telegrama ${ }^{\circ} 01358$ enviado por la Embajada brasileña en Santiago (Chile) en 09 de diciembre. Itamaraty (2015f). Telegrama $n^{\circ} 01310$ enviado por la Embajada brasileña en Santiago (Chile) en 24 de noviembre. Itamaraty (2015g). Telegrama $n^{\circ} 00371$ enviado por el MRE a la Embajada brasileña en Santiago (Chile) 30 de junio.

Itamaraty. (2014a). Reunião Informativa de Ministros das Relações Exteriores dos Estados Partes do MERCOSUL e dos Países Membros da Aliança do Pacífico-Cartagena das Índias, $1^{\circ}$ de novembro de 2014. Recuperado el 14 de diciembre de 2020 de https://www.gov.br/mre/ptbr/canais_atendimento/imprensa/ notas-a-imprensa/reuniao-informativa-de-ministros-das-relacoes-exteriores-dos-estados-partes-do-mercosul-e-dos-paises-membros-da-alianca-do-pacifico-cartagena-das-indias1-de-novembro-de-2014

Itamaraty. (2014b). Telegrama n 00428 enviado por la Embajada brasileña en Santiago (Chile) en 02 de abril.

Itamaraty. (2014c). Telegrama no 00267 enviado por la Embajada brasileña en Santiago (Chile) en 04 de marzo.

Itamaraty. (2014d). Visita do Ministro das Relações Exteriores ao Chile Santiago, 6 de maio de 2014. Recuperado el 14 de diciembre de 2020 de http://webcache.googleusercontent.com/search?q=cache:IExQSBASKm4J:www.itamaraty.gov.br/pt-BR/ 
notas-a-imprensa/4929-visita-do-ministro-das-relacoes-exteriores-ao-chile-santiago-6-de-maio-de-2014+\&c$\mathrm{d}=1 \& \mathrm{hl}=\mathrm{pt}-\mathrm{BR} \& \mathrm{ct}=\mathrm{clnk} \& \mathrm{gl}=\mathrm{br}$

Itamaraty (2014e). Ato assinado por ocasião da visita ao Brasil da presidenta da República do Chile, Michelle Bachelet - Brasília, 12 de junho de 2014. Recuperado el 14 de diciembre de 2020 de http://webcache.googleusercontent.com/search?q=cache:24id3VNqMIcJ:www. itamaraty.gov.br/pt-BR/notas-a-imprensa/5022-ato-assinado-por-ocasiao-da-visita-ao-brasil-da-presidenta-da-republica-do-chile-michelle-bachelet-brasilia-12-de-junho-de$2014+\& \mathrm{~cd}=1 \& \mathrm{chl}=\mathrm{pt}-\mathrm{BR} \& \mathrm{ct}=\mathrm{clnk} \&-$ $\mathrm{gl}=\mathrm{br}$.

Itamaraty (2014f). Telegrama $\mathrm{n}^{\circ} 00597$ enviado por el MRE a la Embajada brasileña en Santiago (Chile) en 06 de agosto.

Itamaraty (2013a). Telegrama ${ }^{\circ} 00773$ enviado por la Embajada brasileña en Santiago (Chile) en 23 de julio.

Itamaraty (2013b). Telegrama ${ }^{\circ} 01348$ enviado por la Embajada brasileña en Santiago (Chile) en 20 de diciembre.

La Tercera (2020). Piñera en cumbre del Mercosur: "Estamos enfrentando los tiempos más difíciles y más adversos de nuestra historia". 2 de julio. Recuperado el 14 de diciembre de 2020 de https:/www.latercera.com/politi$\mathrm{ca} /$ noticia/pinera-en-cumbre-del-mercosur-estamos-enfrentando-los-tiempos-mas-dificiles-y-mas-adversos-de-nuestra-historia/5 JPXJYJ2S5CSRGXU327UZ2W3MI/.
La Tercera (2019a). Ernesto Araújo, canciller de Brasil: "La creación de Prosur es muy necesaria, no tiene sesgo ideológico”. 22 de marzo. Recuperado el 14 de diciembre de 2020 de https:// www.latercera.com/politica/noticia/ ernesto-araujo-canciller-brasil-la-creacion-prosur-necesaria-no-sesgo-ideologico/581106/

La Tercera (2019b). Piñera rechaza dichos de Bolsonaro contra Bachelet y pide a Alta Comisionada justificar afirmaciones por DD.HH. en Brasil. 04 de septiembre. Recuperado el 14 de diciembre de 2020 de https:// www.latercera.com/politica/noticia/ pinera-rechaza-bolsonaro-bachelet-pide-alta-comisionada-justificar-afirmaciones-ddhh-brasil/810054/

Malamud, A. y Gardini, G. (2012). "Has Regionalism Peaked? The Latin American Quagmire and its Lessons" [versión electrónica]. Italian Journal of International Affairs, Vol.47, no. 1 pp. 116-133. Recuperado el 28 de junio de 2021 de https://www.tandfonline. com/doi/abs/10.1080/03932729.201 2.655013

Mariano, M. (2017). “A crise doméstica do Brasil e a política externa do governo Temer”. In: Bizzozero, Lincoln; Férnandez Luzuriaga, Wilson (Orgs.). Anuario política internacional \& política exterior 2016-2017, pp. 99-106. Montevidéu: Cruz del Sur

Mariano, M. (2016). “La política exterior brasileña y los procesos de integración regional a partir de la creación de la UNASUR y la Alianza del Pacífico”. In: Pastrana, Eduardo.; Jost, Stefan 
(Orgs.). Incidencias Regionales y Globales de la Alianza del Pacífico, pp. 205-227. Cidade do México: Fundación Konrad Adenauer, A.C México.

Mercosur (2018a). Plano de Ação de Puerto Vallarta entre os países da Aliança do Pacífico e do MERCOSUL. Recuperado el 14 de diciembre de 2020 de http://www.itamaraty.gov.br/ images/PuertoVallarta/Plano-de-Acaode-Puerto-Vallarta-PORT.pdf.

Mercosur. (2018b). Declaração entre os Estados Partes do Acordo Marco da Aliança do Pacífico (AP) e os Estados Partes do Mercosul signatários do Tratado de Assunção. Recuperado el 14 de diciembre de 2020 de http:// www.itamaraty.gov.br/images/PuertoVallarta/FinalFinalDeclaracaoVallartaPORT.pdf

Mercosur. (2015a). Ata 01/15 de la XCVII Reunión Ordinaria del Grupo Mercado Común. Recuperado el 14 de diciembre de 2020 de https://documentos.mercosur.int/

Mercosur (2015b). Ata 02/15 de la XCVIII Reunión Ordinaria del Grupo Mercado Común. Recuperado el 14 de diciembre de 2020 de https://documentos.mercosur.int/

Milani, C. y Pinheiro, L. (2017). “The Politics of Brazilian Foreign Policy and Its Analytical Challenges" [versión electrónica]. Foreign Policy Analysis, Vol. 13, no. 2, pp. 278-296. Recuperado el 12 de diciembre de 2020 de https://academic.oup.com/fpa/article-abstract/13/2/278/2625540?redirectedFrom $=$ fulltext .
Ministerio de Relaciones Exteriores (2019). Canciller Ribera encabeza reunión del mecanismo $2+2$ con Brasil. https://minrel.gob.cl/minrel/ noticias-anteriores/canciller-ribera-encabeza-reunion-del-mecanismo-2-2-con-brasil

Ministerio de Relaciones Exteriores (2016). Recuperado el 14 de diciembre de 2021 de https://www.minrel. gov.cl/comunicado-de-prensa-por-sucesos-politicos-en-brasil/minrel_ old/2016-05-12/082353.html

O Estado de S. Paulo (2018). Bolsonaro enviou telegrama a filho de Augusto Pinochet em que fala em "saudoso" general. Recuperado el 14 de diciembre de 2020 de https://politica.estadao.com. br/noticias/eleicoes, bolsonaro-enviou-telegrama-a-filho-de-augusto-pinochet-em-que-fala-em-saudoso-general,70002519099

Orjuela, D. y Chenou, J.M. (2019). “Regionalism and presidential ideology in the current wave of Latin American integration". International Area Studies Review, Vol. 22, no. 1, pp. 41-63. Recuperado el 14 de diciembre de 2021 de https://journals.sagepub.com/ doi/10.1177/2233865918815008

Oyarzún, L. y Rojas, F. (2013). “La Alianza del Pacífico en América Latina ¿Contrapeso regional?” [versión electrónica]. Cuadernos sobre Relaciones Internacionales, Regionalismo y Desarrollo, Vol. 8, no. 16, pp. 9-30. Recuperado el 12 de diciembre de 2020 de https://www.researchgate.net/publication/281828691_La_Alianza_del_Pa- 
cifico_en_America_Latina_Contrapeso_regional.

Oyarzún, L. (2018). “The Pacific in Chile's Foreign Policy: A Tool to Reinforce Open Regionalism" [versión electrónica]. Latin American Policy, Vol. 9, no. 2, pp. 282-303. Recuperado el 28 de junio de 2021 de https://onlinelibrary.wiley.com/doi/abs/10.1111/ lamp.12152

Portal da Indústria (2014). Indústria brasileira se aproxima da Aliança do Pacífico para estimular fortalecimento do comércio bilateral. Recuperado el 14 de diciembre de 2020 de https://webcache.googleusercontent. com/search?q=cache:iuXivF4NksU$\mathrm{J}:$ https://noticias.portaldaindustria. com.br/noticias/economia/industria-brasileira-se-aproxima-da-alianca-do-pacifico-para-estimular-fortalecimento-do-comercio-bilateral/+\&c$\mathrm{d}=1 \& \mathrm{hl}=\mathrm{pt}-\mathrm{BR} \& \mathrm{ct}=\mathrm{clnk} \& \mathrm{gl}=\mathrm{br}$.

Rousseff, D. (2016) Declaração à imprensa da Presidenta da República, Dilma Rousseff, por ocasião da visita ao Chile-Santiago/Chile. Recuperado el 14 de diciembre de 2020 de http://www. biblioteca.presidencia.gov.br/presidencia/ex-presidentes/dilma-rousseff/discursos/discursos-da-presidenta/ declaracao-a-imprensa-da-presidenta-da-republica-dilma-rousseff-por-ocasiao-da-visita-ao-chile-santiago-chile.

Rousseff, D. (2014). Presidenta Dilma concede entrevista a jornais latino-americanos. In: Governo. 22 dez. 2014. Recuperado el 26 de enero de 2019 de http://noticias.i3gov.planejamento.gov.br/ noticias/pesquisa.xhtml? b=\%22Presidenta $\% 20$ Dilma $\% 20$ concede $\% 20$ entrevista $\% 20$ a $\% 20$ jornais $\% 22+$ fontes:()+perfis_facebook:()+perfis_twitter:()+canais:()\&$\mathrm{q}=0 \& \mathrm{o}=0 \& \mathrm{e}=0$.

Salomón, M. y Pinheiro, L. (2013). "Análise de Política Externa e Política Externa Brasileira: trajetória, desafios e possibilidades de um campo de estudos" [versión electrónica]. Revista Brasileira de Política Internacional, Vol.56, no.1, pp. 40-59. Recuperado el 12 de diciembre de 2020 de https://www.scielo.br/scielo.php?pi$\mathrm{d}=$ S0034-73292013000100003\&script=sci_abstract \& $t \operatorname{lng}=p t$

Sanahuja, J. y López, C. (2020). "Las derechas neopatriotas en América Latina: contestación al orden liberal internacional" [versión electrónica]. Revista CIDOB d'Afers Internacionals, no. 126, pp. 41-63. Recuperado el 28 de junio de 2021 de https:// www.cidob.org/es/articulos/revista cidob_d_afers_internacionals/126/ las_derechas_neopatriotas_en_america_latina_contestacion_al_orden_liberal_internacional

Sanahuja, J. (2016). "Regionalismo e integración en América Latina: de la fractura Atlántico-Pacífico a los retos de una globalización en crisis" [versión electrónica]. Pensamiento propio, Vol. 21, no. 44, pp. 29-76. Recuperado el 12 de diciembre de 2020 de http://www.cries.org/wp-content/ uploads/2017/02/007-sanahuja.pdf Saraiva, M. (2020). "The democratic regime and the changes in Brazilian 
foreign policy towards South America” [versión electrónica]. Brazilian Political Science Review, Vol. 14, no. 3, pp. 1-39. Recuperado el 14 de diciembre de 2021 de http://doi.org/10.1590/19813821202000030001

Schafer, M. (1997). "Images and policy preferences” [versión electrónica]. Political Psychology, Vol.18, no. 4, pp. 813819. Recuperado el 28 de junio de 2021 de https://onlinelibrary.wiley.com/doi/ abs/10.1111/0162-895X.00080

Senado Federal (2020). MENSAGEM $N^{o}$ 286. Recuperado el 14 de diciembre de 2020 de https://legis.senado. leg.br/sdleg-getter/documento?d$\mathrm{m}=8114861 \& \mathrm{ts}=1603149520244 \&$ disposition=inline.

Silva, Á. (2020). "Diverse images, reverse strategies: Brazilian foreign ministers' perceptions and the Brazil-Argentina rapprochement (1974-1985)" [versión online]. Revista Brasileira de Política Internacional, Vol. 63, no. 1, pp. 1-20. Recuperado el 12 de diciembre de 2020 de http://www.scielo. br/scielo.php?script=sci_arttext $\&$ pi$\mathrm{d}=$ S0034-73292020000100205\&tlng=en

Silva, A. y Pérez, J. (2019). "Lula, Dilma, and Temer: The Rise and Fall of Brazilian Foreign Policy "[versión electrónica]. Latin American Perspectives, Vol. 46, no. 4, pp. 169-185. Recuperado el 28 de junio de 2021 de https://journals.sagepub.com/doi/ abs/10.1177/0094582X19846521

SUBREI (2020a). Ficha País: Chile-Brasil. Recuperado el 28 de junio de 2021 https://www.subrei.gob. cl/docs/default-source/default-document-library/brasil-anual2019. pdf? sfvrsn=6856f681

SUBREI (2020b). Presencia de inversiones directas de capitales chilenos en el mundo: 1990 - diciembre 2019. Recuperado el 28 de junio de 2021 https:// www.subrei.gob.cl/docs/default-source/estudios-y-documentos/inversiones-directas-en-el-exterior/000_presencia-de-inversiones-chilenas-directas-en-el-mundo_1990-2019_ sept2020.pdf? sfvrsn=d63e1341

Temer, M. (2018). O Brasil no mundo: escritos de diplomacia presidencial (2016-2018). Brasília: FUNAG. Recuperado el 14 de noviembre de 2021 de http://funag.gov.br/loja/ download/o-brasil-no-mundo-abertura-e-a-responsabilidade.pdf.

Uo. (2020). Chile sondou inteligência brasileira para achar origem de protestos em 2019. 8 de octubre. Recuperado el 14 de diciembre de 2020 de https://noticias.uol.com.br/internacional/ultimas-noticias/2020/10/08/ chile-pediu-ajuda-a-inteligencia-brasileira-nos-protestos-de-2019.htm

Valor Econômico (2018). Temer fala de relação comercial forte com Chile na posse de Piñera. Recuperado el 14 de diciembre de 2020 de https://www. valor.com.br/internacional/5376991/ temer-fala-de-relacao-comercial-forte-comchile-na-posse-de-pinera.

Valor Econômico (2017). Bachelet vem ao Brasil, mas não encontra Temer. $10 \mathrm{de}$ octubre de 2017. Recuperado el 14 de diciembre de 2021 de https://valor.globo.com/mundo/noticia/2017/10/10/ 
Evolución de las relaciones bilaterales entre Brasil y Chile desde la política "Convergencia en la Diversidad"

bachelet-vem-ao-brasil-mas-nao-en- Wehner, L. y Thies, C. (2014). "Role contra-temer.ghtml. Theory, Narratives and Interpreta-

Wehner, L. (2016). "Inter-Role Conflict, tion: The Domestic Contestation of Role Strain and Role Play in Chile's Roles”. International Studies Review, Relationship with Brazil” [versión Vol. 16, no. 3, pp. 411-436. Recupeelectrónica]. Bulletin of Latin Amerirado el 28 de junio de 2021 de https:// can Research, Vol. 35, No. 1, pp. 6477. Recuperado el 28 de junio de 2021 de https://onlinelibrary.wiley.com/doi/ full/10.1111/blar.12413 academic.oup.com/isr/article-abstract/16/3/411/1821860? redirectedFrom=fulltext 
